\title{
OROGENIAS PALEOZÓICAS NO DOMÍNIO SUL-OCIDENTAL DO GONDWANA E OS CICLOS DE SUBSIDÊNCIA DA BACIA DO PARANÁ
}

\author{
EDISON J. MILANI* \& VICTOR A. RAMOS**
}

\begin{abstract}
PALEOZOIC OROGENIES IN THE SOUTHWESTERN DOMAIN OF GONDWANA AND THE SUBSIDENCE CYCLES OF THE PARANA BASIN The geological development of the Parana Basin was influenced by the geodynamics of southwestern Gondwana, a domain continuously affected during almost all the Phanerozoic eon by compressional stresses derived from a persistently active convergent motion between the continental block and the oceanic lithosphere of Panthalassa. The Parana Basin was supported by a cratonic basement since its inception, but had in its neighbourhood evolving collisional belts fringed by foreland basins.

Some areas were selected representing the history of subsidence along the foreland domain of southwestern Gondwana during Paleozoic times. The subsidence analysis showed that such foreland basins experienced cycles of accelerated subsidence that coincide in time with the major orogenic phases, that were related to the docking of terranes along the margin of the continent. The computation of average subsidence rates revealed the main subsidence cycles for the region as a whole.

Subsidence and sediment accumulation in the Parana Basin started during Middle to Late Ordovician times when the Precordillera terrane collided against Gondwana and produced the different contractional phases of the Ocloyic Orogeny. The intraplate response to the compressional stresses related to this orogenic cycle was transtensional reactivation of weakness zones, providing the initial subsidence for the Parana Basin. Repeatedly during the geologic history of the Parana Basin orogenic cycles left their signature as periods of accelerated subsidence. Subsidence plots revealed that Early Devonian times, when the stresses generated by the Precordilleran Orogeny affected Gondwana, and Late Permian times, under the yoke of the Sanrafaelic Orogeny, were periods when intracratonic subsidence rates increased remarkably.

An integrated analysis of the sedimentary record of the Parana Basin, considering eustatic variations of the sea level and subsidence cycles of southwestern Gondwana led to the conclusion that the stratigraphic cyclicity observed in the Parand Basin was ultimately influenced by its subsidence history. The presumed global correlation peaks shown in Vail's curve, of Late Silurian, Early Carboniferous and Early Permian ages, are not present in the Parana Basin. Instead, local maximum flooding levels developed in each one of the second order transgressive cycles, during Early Silurian, Early Devonian and Late Permian times, defining the particular subsidence history of this interior basin as an intraplate response to geodynamic processes affecting southwestern Gondwana margin.
\end{abstract}

Keywords: Parana Basin, Southwestern Gondwana, tectonics and sedimentaton

RESUMO A evolução geológica da Bacia do Paraná foi marcantemente influenciada pela geodinâmica do domínio sul-ocidental do Gondwana. Esta foi uma região continuamente submetida, durante praticamente todo o Fanerozóico, a esforcos de natureza compressiva derivados da relação de convergência mantida entre o bloco siálico gondwânico e a litosfera oceânica do Panthalassa. A Bacia do Paraná, embora suportada por um embasamento cratônico desde sua implantação, teve em sua vizinhança ativos cinturões colisionais e bacias de antepaís a eles relacionadas. Algumas áreas foram selecionadas como representativas do comportamento da subsidência durante o Paleozóico ao longo do domínio de antepaís do Gondwana sul-ocidental. A análise de subsidência mostrou que tais bacias de antepaís experimentaram ciclos de subsidência acelerada que coincidem temporalmente com as principais fases orogênicas, estas relacionadas à aglutinação de terrenos alóctones ao paleocontinente. O cálculo de taxas médias de subsidência revelou os principais ciclos de subsidência para a região como um todo.

A subsidência e a acumulação sedimentar na Bacia do Paraná iniciaram durante o Meso a Neo-Ordoviciano, tempo em que o terreno da Precordilheira colidiu contra o Gondwana e produziu a Orogenia Oclóyica. A resposta no domínio intraplaca aos esforcos compressivos derivados desse ciclo orogênico foi na forma de reativação transtensiva de zonas de fraqueza, o que patrocinou a subsidência inicial da Bacia do Paraná Repetidamente durante sua história geológica, a Bacia do Paraná experimentou ciclos de subsidência acelerada induzidos por episódios orogênicos. A análise de subsidência revelou que o Eodevoniano, quando os esforços gerados pela Orogenia Precordilheirana afetaram o Gondwana, e o Neopermiano, sob o jugo da Orogenia Sanrafaélica, foram períodos em que as taxas de subsidência intracratônica cresceram marcadamente.

Uma análise integrada do registro estratigráfico da Bacia do Paraná, considerando variacões eustáticas do nível do mar e os ciclos de subsidência do Gondwana sul-ocidental, conduziu à conclusão de que a ciclicidade observada na Bacia do Paraná foi, em última instância, controlada por sua história de subsidência. Os picos de uma presumida correlação global mostrados na curva de Vail, supostamente representativos de altos eustáticos no Neossiluriano, Eocarbonífero e Eopermiano, não estão documentados na Bacia do Paraná. Por seu turno, níveis de máxima inundação de caráter local, inerentes ao domínio considerado, desenvolveram-se em cada um dos ciclos transgressivo-regressivos encontrados na bacia, e correspondem a pacotes pelíticos com idades eossiluriana, eodevoniana e neopermiana. Assim, os ciclos de subsidência da Bacia do Paraná parecem configurar a resposta intraplaca à geodinâmica particular da margem sul-ocidental do Gondwana.

Palavras-chave: Bacia do Paraná, Gondwana, tectônica e sedimentação

INTRODUÇÃO A Bacia do Paraná (Fig. 1), uma vasta região de sedimentação situada na porção centro-oriental da América do Sul, evoluiu durante o Paleozóico e o Mesozóico e abriga um registro estratigráfico temporalmente posicionado entre o Neo-Ordoviciano e o Neocretáceo, documentando assim quase 400 milhões de anos da história geológica fanerozóica dessa região do planeta. Seis unidades aloestratigráficas de segunda ordem ou superseqüências (Milani 1997) são reconhecidas (Fig. 1): Rio Ivaí (Caradociano-Landoveriano), Paraná (Lockoviano-Frasniano), Gondwana I (WestfalianoScythiano), Gondwana II (Anisiano-Noriano), Gondwana III (Neojurássico-Berriasiano) e Bauru (Aptiano-Maestrichtiano). Três delas correspondem a ciclos transgressivo-regressivos paleozóicos, e as demais são pacotes sedimentares continentais mesozóicos com rochas ígneas associadas. Estas superseqüências constituem o registro remanescente de sucessivas fases de acumulação sedimentar que se alternaram a épocas de erosão generalizada.

A Bacia do Paraná, em função de aspectos inerentes a seu posicionamento geotectônico atual e a suas características tectono-sedimentares, é considerada uma típica bacia intracratônica. $\mathrm{O}$ conceito de "bacia cratônica", temática cujos diversos aspectos foram sintetizados por Leighton \& Kolata (1990), implica uma região de sedimentação suportada por um embasamento consolidado, um domínio crustal caracterizado por elevada resistência a esforços originados em margens de placas. Os mecanismos de subsidência de sinéclises intrac- ratônicas são ainda controversos e muito pouco compreendidos. Uma vez que tais regiões situam-se distantes de margens de continentes, desta forma estando desacopladas de mecanismos tectônicos originados pela interação de placas, a origem e o desenvolvimento de bacias intracratônicas são frequentemente explicadas por combinações de fenómenos tais como "distensão continental, subsidência térmica sobre uma ampla área e reajustes isostáticos tardios" (Klein 1995), processos estes de precário controle geológico-geofísico.

Para uma bacia em particular, entretanto, o fato de situar-se no interior de um continente não significa necessariamente uma condição permanente e imutável desde sua implantação. Isto é especialmente verdadeiro para o caso da Bacia do Paraná. Ó crescimento da litosfera continental ao longo da margem sul do Gondwana foi um importante processo durante o Fanerozóico, favorecendo um contexto de fechamento progressivo do interior do continente a incursões marinhas. A Bacia do Paraná, originada como um golfo (Zalán et al. 1990, Milani 1992) aberto para o Panthalassa, tornou-se com o tempo uma depressão intracratônica aprisionada no interior do Gondwana.

Neste trabalho, procurou-se correlacionar a amplitude temporal dos ciclos de subsidência da Bacia do Paraná àqueles observados no domínio de antepaís adjacente, no sentido de calibrar os mais importantes períodos de subsidência numa escala continental. A análise de subsidência revelou episódios notavelmente síncronos de subsidência acelerada envolvendo tanto o antepaís quanto o domínio intra-

* Petróleo Brasileiro S.A. PETROBRAS/E\&P/GEREX/GEIEST, Av. Chile, 65, 13 andar, 20035.900 Rio de Janeiro/RJ/Brasil, E-mail: ejmilani@ep.petrobras.com.br

** Dep. de Ciências Geológicas, Universidad de Buenos Aires, Ciudad Universitária, Pabellon II, 1428 Nunez/Buenos Aires/Argentina, E-mail: andes@tango.gl.fcen.uba.ar 


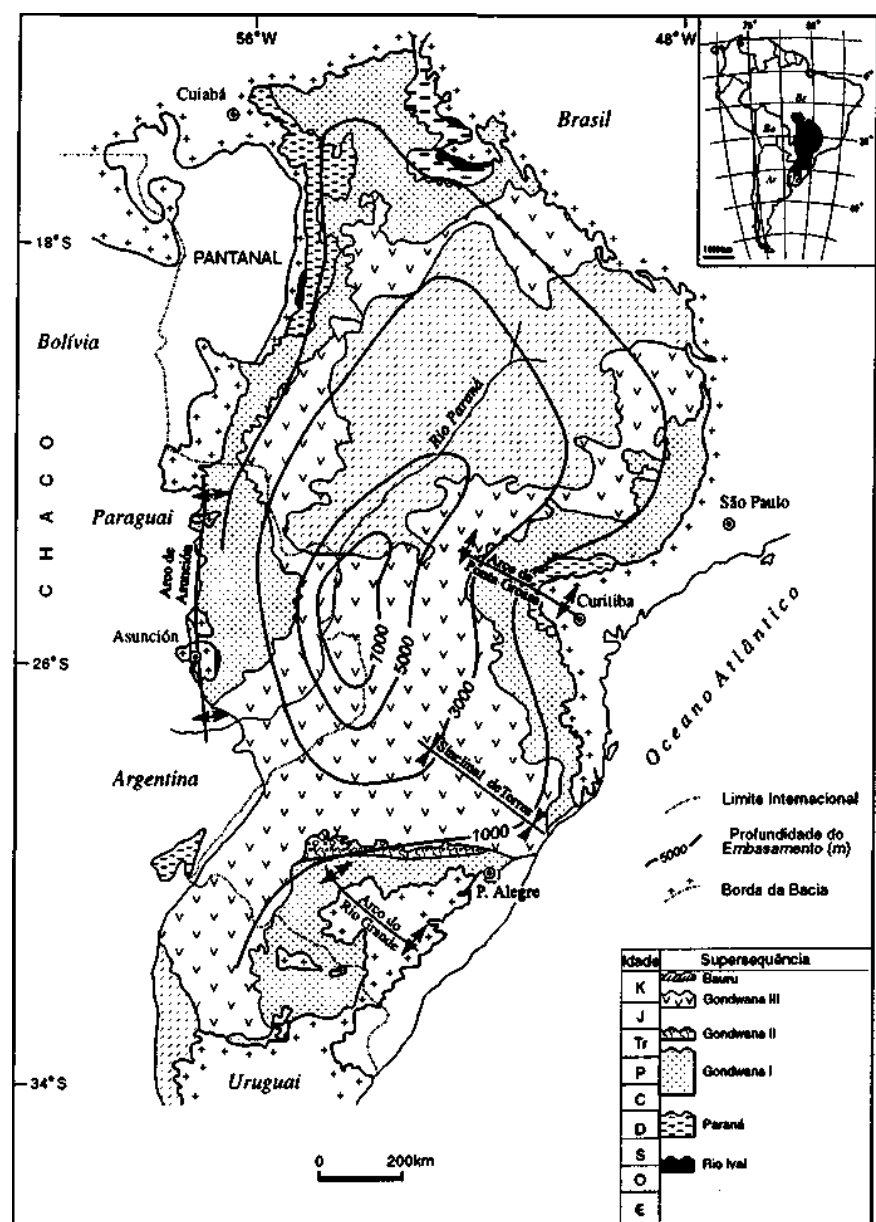

Figura l - Mapa geológico simplificado da Bacia do Paraná, e distribuição no tempo das diversas unidades de seu registro estratigráfico.

cratônico, sugerindo que estas áreas possam ter compartilhado durante sua evolução geológica alguns mecanismos de subsidência, atuantes em ampla escala.

TECTÔNICA E SEDIMENTAÇ̃̃O NO CONTEXTO REGIONAL A margem meridional do Gondwana, em particular o trecho que hoje em dia corresponde à borda andina da América do Sul, comportou-se durante praticamente todo o Fanerozóico como um domínio de convergência entre o bloco siálico e a litosfera oceânica do Panthalassa (Bahlburg and Breitkreuz 1991, Gohrbandt 1993). Uma série de terrenos alóctones alcançaram essa região, e sua aglutinação à margem gondwânica produziu importantes episódios orogênicos (Ramos 1988, 1990). O regime compressivo aí persistentemente atuante influenciou a evolução de faixas dobradas e bacias de antepaís adjacentes às mesmas, mas afetou também o interior cratônico do continente (Zalán et al. 1990, Assine 1996, Milani 1997), como será exposto adiante.

Dois domínios distintos devem ser considerados ao se analisar a tectônica e sedimentação no Gondwana sul-ocidental; sua porção cratônica, correspondente ao núcleo do paleocontinente e constituída por um complexo mosaico de blocos crustais aglutinados e ligados entre si até o Cambriano (Powell 1993); de outro lado os Gondwanides (Keidel 1916), uma extensa faixa de orógenos do Fanerozóico e bacias associadas distribuídas ao longo da margem meridional do Gondwana (Fig. 2), unidade geotectônica essa também denominada como "geossinclinal Samfrau" por Du Toit (1927) e modernamente cartografada por De Wit et al. (1988). A Bacia do Paraná desenvolveu-se sobre o Gondwana cratônico, mas ao lado da zona móvel dos Gondwanides, experimentando assim uma influência dos esforços compressivos originados pela convergência de placas ao longo da faixa de colisão.

A sucessão de orogenias que marcaram a história fanerozóica do Gondwana sul-ocidental, resumida por Ramos (1988), compreendeu dois ciclos tectono-sedimentares principais: Famatiniano (Ordoviciano a Devoniano) e Gondwânico (Carbonífero a Triássico). O Ciclo
Famatiniano compreende dois pulsos de deformação compressiva e fenómenos sedimentares e magmáticos associados, as orogenias Oclóyica e Precordilheirana, e o Ciclo Gondwânico inclui as orogenias Chanica e Sanrafaélica.

Uma das características marcantes da geologia sedimentar fanerozóica do domínio meridional do Gondwana é sua natureza siliciclástica (França et al. 1995). Uma das exceções a essa regra é encontrada na Precordilheira argentina. A presença de uma espessa sequência de carbonatos portando típicos exemplares da fauna cambriana de Olenellus (Borrello 1965) apoiada sobre um embasamento com afinidades à província de Greenville do Proterozóico da América do Norte, e estando o bloco assim caracterizado separado das regiões vizinhas por importantes suturas geotectônicas (Ramos et al. 1996), constituem fatos que levaram à interpretação de ser a Precordilheira um terreno alóctone que consolidou-se inicialmente no domínio da Laurásia, dela separou-se e afastou-se, para finalmente colidir contra o Gondwana (Ramos et al. 1986, Astini et al. 1995, Astini 1996). A colisão desse terreno, estimada como tendo ocorrido em torno do Meso a Neo-Ordoviciano, produziu o conjunto de fenómenos conhecidos na Argentina e Bolívia como Orogenia Oclóyica. Um segundo e também importante ciclo de deformação compressiva é reconhecido na região da Precordilheira como Orogenia Precordilheirana (Furque 1965, Astini 1996), responsável por um significativo incremento paleobatimétrico na bacia de antepaís e pela acumulação de uma possante sucessão de turbiditos com até 2.200 metros de espessura, correspondentes à Formação Punta Negra, do Emsiano-Givetiano. O contexto geodinâmico da Orogenia Precordilheirana não está bem estabelecido. Astini (1996) atribui este episódio à colisão de um bloco siálico conhecido como Chilenia (Ramos et al. 1984).

Muitas questões pertinentes à história colisional paleozóica da margem gondwânica ainda estão em aberto, e uma delas diz respeito à cronologia da colisão do terreno Chilenia. Admitido como um evento eodevoniano por alguns autores, como acima discutido, o fenômeno é interpretado por outros pesquisadores (Ramos et al. 1984, Ramos 1988) como tendo ocorrido já no Eocarbonífero. O ciclo de deformação correspondente, neste caso, é conhecido como Orogenia Chanica. Antigas zonas de sutura no antepaís (Fernández-Seveso \& Tankard 1995) experimentariam reativação transtensiva sob os esforços da Orogenia Chanica, servindo este como o mecanismo iniciador da subsidência para o Ciclo Gondwânico, que se desenvolveria a seguir. As unidades mais superiores do ciclo tectono-sedimentar-magmático Gondwânico representam o clímax do vulcanismo de arco e sedimentacão vulcanoclástica continental associada, ocorrida entre 275 e 250 Ma (Kay et al. 1989, López-Gamundí et al 1994). Tais depósitos apoiam-se discordantemente sobre as sequências precedentes e sua acumulação acompanhou os movimentos da Orogenia Sanrafaélica.

Subsidência no domínio de antepaís A região meridional do Gondwana constituiu um limite ativo de placas durante o Fanerozóico. Esta extensa e segmentada faixa assistiu à interação da placa continental com a litosfera oceânica do Panthalassa e com uma série de terrenos alóctones. A atual margem andina da América do Sul exibe condições similares em termos de regime tectônico compressivo e processos orogênicos, de tal sorte que as condições gerais em termos fisiográficos, o magmatismo e os processos geradores de bacias sedimentares que podem hoje ser lá observados reproduzem os fenómenos dominantes na história geológica pretérita da região. Assim, da mesma maneira em que o desenvolvimento do cinturão Andino causa a subsidência flexural observada no oeste da América do Sul -a bacia do Chaco da Bolívia e Argentina - os orógenos paleozóicos influenciaram o desenvolvimento das bacias de antepaís adjacentes. A análise de subsidência destas bacias de antepais pode revelar importantes parâmetros à interpretação tectônica regional.

Quatro áreas (Fig. 2) foram selecionadas como representativas dos vários aspectos da evolução de bacias sedimentares e seu relacionamento com a história tectônica dos Gondwanides: o Chaco boliviano, a região da Precordilheira-Bacia de Paganzo e a Bacia de Sauce Grande faixa dobrada das Sierras Australes na Argentina e as bacias do Cabo-Karoo-faixa dobrada do Cabo na África do Sul.

Sucessões paleozóicas são espessas e de ocorrência ampla na Bolívia, compreendendo cinco superseqüências relacionadas a momentos específicos na evolução da bacia de sedimentação. Tacsara, Chuquisaca, Villamontes, Cuevo e Serere são as unidades aloestratigráficas reconhecidas por Sempere (1995), incluindo pacotes sedimentares dominantemente terrígenos que se distribuem do Cambriano terminal ao Eotriássico (Fig. 3). Os calcários e dolomitos pensilvanianos-eopermianos do Grupo Copacabana (Díaz-Martínez 1995), per- 
tencentes \& Superseqiiencia Cuevo, incluem-se entre as escassas ocorrencias de rochas carbonaticas do Gondwana sul-ocidental.

Outra ocorrencia de carbonates, estes cambro-ordovicianos, e a da regiao da Precordilheira argentina, na forma de uma espessa sec. ao de sedimentos de plataforma. Os carbonates da Precordilheira fazem parte de um fragmento da Laurasia que foi aglutinado ao Gondwana do Meso ao Neo-Ordoviciano. Na sucessao estratigráfica, sobrepõe-se aos carbonates um pacote de rochas siliciclasticas siluro-devonianas portadoras das faunas endemicas do Gondwana, no conjunto representando o Ciclo Famatiniano de evolucão dos Gondwanides (Ramos 1990). O Ciclo Gondwânico acumulou-se a seguir, estando registrado com suas maiores espessuras nas bacias de Calingasta-Uspallata e Paganzo no oeste da Argentina (López-Gamundí et al. 1994).

A Bacia de Sauce Grande-faixa dobrada das Sierras Australes na Argentina, e Cabo-Karoo e a faixa dobrada do Cabo na Africa do Sul (Fig. 3), faixas orogênicas com bacias de antepaís associadas, compartilham uma série de atributos geológicos, fruto de sua evolução comum (López-Gamundi \& Rossello, no prelo). A evolução pre-carbonífera em ambas as regiões e documentada por um espesso pacote de sedimentitos siliciclasticos com idade entre o Ordoviciano e o Devoniano, que tiveram por fonte as áreas cratonicas situadas a norte (Andreis et al. 1989, Johnson 1991). Uma discordância angular aparta esses estratos dos sedimentitos gondwânicos, que incluem depositos relacionados à glaciação neocarbonífera-eopermiana (Visser 1990) seguidos por uma sucessão de rochas sedimentares e vulcanoclásticas sinorogênicas de idade permiana a eotriássica (Cole 1992, López-Gamundí et al. 1995).

Curvas de subsidência são ferramentas muito úteis na análise de bacias sedimentares. $\mathrm{O}$ formato de uma curva, representando variações nas taxas de subsidência com o tempo, reflete um regime tectônico particular (Williams 1995), e pode ser utilizado como um elemento de correlação interregional. No dominio de antepaís, a subsidência e primordialmente induzida pela sobrecarga flexural imposta a litosfera continental pelo cinturão montanhoso em desenvolvimento, de tal sorte que variações nas taxas de subsidência (aceleração-desaceleração) podem ser diretamente relacionadas a pulsos de deformação compressiva ao longo da margem ativa de placas. Um ciclo orogênico ideal seria registrado na história de subsidência do antepaís por um ciclo complete crescente-decrescente de taxas de subsidência (Fig. 4). Este conceito foi aqui empregado como chave na correlação interregional de eventos tectônicos, e na interpretação do desenvolvimento de sequências estratigráficas no domínio intracratônico.

A historia de subsidência no antepaís paleozóico do Gondwana sul-ocidental foi integrada pela utilização de informações das quatro áreas de referência acima citadas (Milani 1997). Algumas curvas foram computadas por meio da técnica de backstripping (Steckler \& Watts 1978) e, em conjunto a gráficos disponíveis na bibliografia, foram combinados numa curva de subsidência composta (Fig. 5), ilustrativa da variafao com o tempo da taxa média de subsidência. As taxas médias de subsidência foram obtidas aritmeticamente a partir de

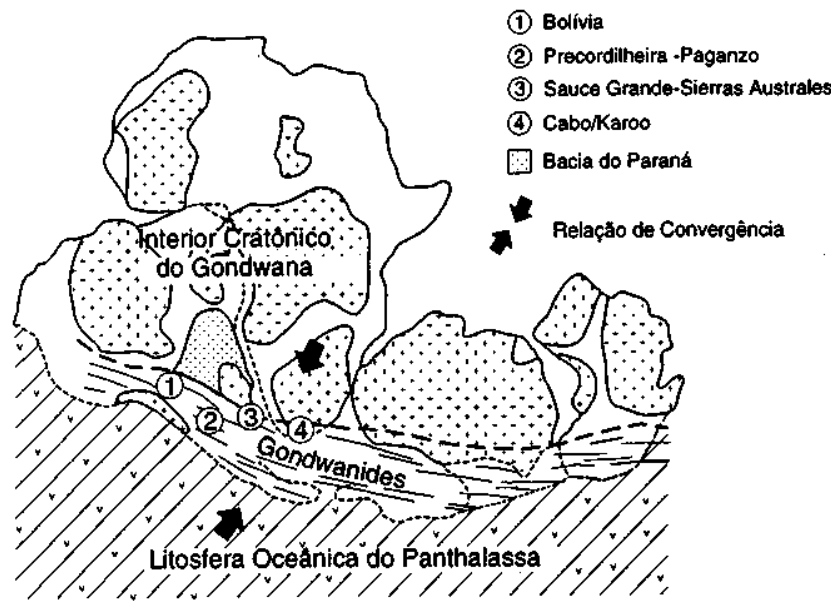

Figura 2- Contexto geotectônico fanerozóico da margem sul do Gondwana, um sitio de persistente convergência entre o paleocontinente e o assoalho oceânico do Panthalassa. Compilado de Powell (1993) e De Wit et al. (1988), segundo a concepção de Du Toit (1927). Números de l a 4 correspondem às áreas de referência utilizadas na análise de subsidência da faixa Gondwanides. dados de cada uma das quatro áreas, considerados segundo intervalos variáveis de tempo geológico, o que resultou em uma sucessão de ciclos interpretados como representativos do comportamento oscilatório da litosfera para o domínio de antepaís, produto de um contexto geodinâmico particular em que vários episódios de colisão sucederam-se no tempo.

Sob esta abordagem, as variacões nas taxas de subsidência observadas no domínio de antepaís, ilustradas na curva de subsidência composta, são interpretadas como tendo sido induzidas pela variação na intensidade da atividade tectônica ao longo da faixa orogênica, constatando-se uma notável coincidência temporal entre tais ciclos aqui estabelecidos e os conhecidos períodos orogênicos identificados na geologia do Gondwana sul-ocidental, como anteriormente discutidos. Adiante, o conceito de ciclos de subsidência será utilizado como suporte à interpretação do desenvolvimento de sequências estratigráficas em escala regional.

A BACIA DO PARANÁ Estrutura do embasamento Diversos poços já amostraram o embasamento da Bacia do Paraná. Em conjunto com informações geofisicas e dados de afloramentos, permitiram interpretações acerca da natureza, estrutura e idade desta região da crosta continental do planeta. Estudos precedentes (Cordani et al.

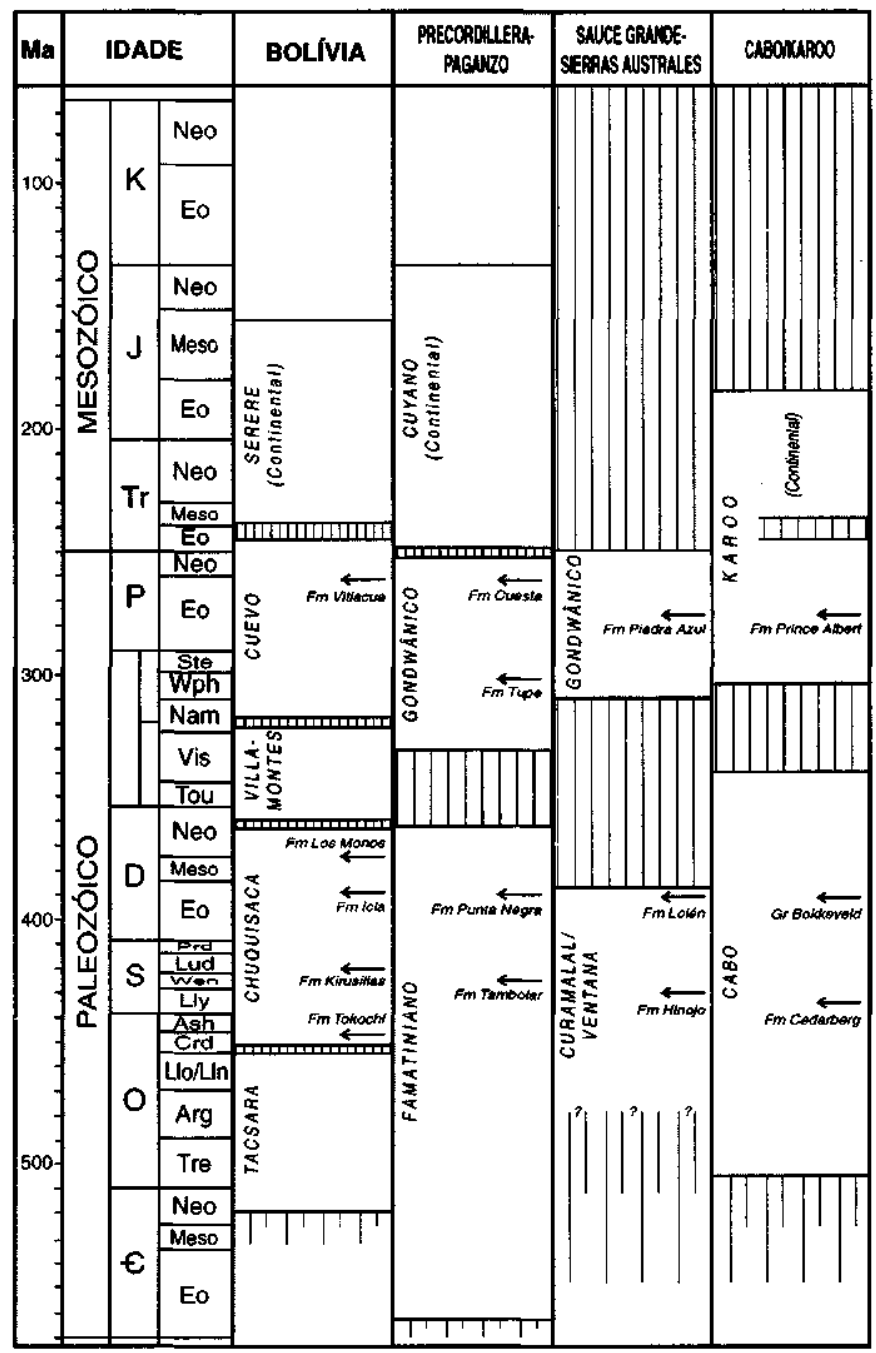

Figura 3 - Correlação estratigráfica entre as quatro áreas de referência utilizadas neste trabalho. Fontes dos dados para a Bolivia: Sempere (1995); Precordilheira-Paganzo: Ramos (1990), FernándezSeveso \& Tankard (1995), e Kokogian et al. (1993); Sauce GrandeSierras Australes: López-Gamundi et al. $(1994,1995)$ e Iniguez et al. (1989); Cabo/Karoo-faixa dobrada do Cabo: Veevers et al. (1994) e Cole (1992). Setas indicam momentos de importantes inundações marinhas. Denominações estratigráficas referem-se a unidades clássicas reconhecidas em cada área. Localização das seções é mostrada na Figura 2. Escala de tempo geológico segundo Cowie \& Bassett(1989). 
1984, Zalán et al 1990, Soares 1991) descreveram o assoalho da Bacia do Paraná como constituído por um "núcleo cratônico" central circundado por faixas móveis brasilianas. Tal interpretação implica a existência de um domínio estável justamente na região central da sinéclise, um fato que não se ajusta à história de subsidência da bacia. Na realidade, a porção central da Bacia do Paraná abriga as maiores espessuras de quase todas as suas superseqüências, como será mostrado adiante.

Interpretações de dados geofísicos em escala de bacia, recentemente efetuadas (Marques et al. 1993), revelaram uma persistente orientação SW-NE de anomalias gravimétricas e magnetométricas marcando toda a área da bacia, provavelmente relacionado à estruturação do embasamento. Dados de sísmica de reflexão igualmente detectaram um padrão SW-NE de estruturas, configuradas como calhas na região central da bacia e alojando seu pacote paleozóico mais inferior, pré-devoniano. Tal feição foi denominada por Marques et al. (1993) como "rifte central" (Fig. 6), ajustando-se adequadamente às anomalias gravimétricas e magnetométricas dessa mesma região.

Milani (1997) mostrou uma interpretação para o arranjo geométrico dominantemente SW-NE do embasamento da Bacia do Paraná (Fig. 7). Um poço profundo perfurado no contexto do "rifte central" da
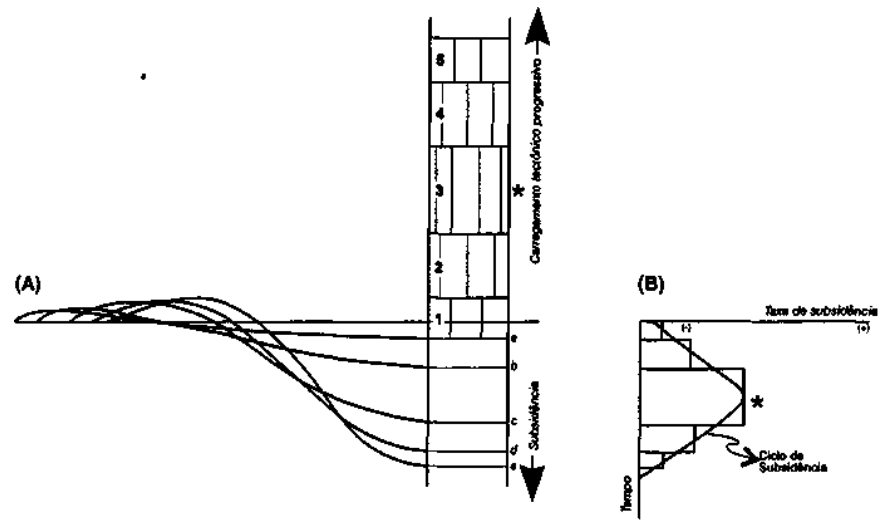

Figura 4 - (A) Esquema ilustrativo do relacionamento entre a subsidência flexural num domínio de antepaís e a variação da carga tectônica aplicada à margem de uma placa. Os números 1-5 representam a espessura do cinturão montanhoso em cinco intervalos temporais de sua história evolutiva; letras a-e mostram a subsidencia cumulativa produzida por tal carga tectônica. (B) Variação nas taxas de subsidência num domínio de antepaís como resultado de um ciclo orogênico completo.
Bacia do Paraná amostrou um corpo de basalto com rochas vulcanoclásticas associadas, que ocorrem intercaladas aos sedimentos mais inferiores (ordovício-silurianos) da bacia. O "basalto Três Lagoas" constitui uma ocorrência até agora singular de material ígneo paleozóico na Bacia do Paraná (Mizusaki 1989), mas que guarda um particular significado para o entendimento dos mecanismos iniciais de subsidência da bacia.

Arcabouco estratigráfico Seis unidades aloestratigráficas de segunda ordem, ou superseqüências na concepcão de Vail et al (1977), cada uma delas compreendendo um registro geológico da ordem de algumas dezenas de milhões de anos, constituem o arcabouço estratigráfico da Bacia do Paraná (Milani 1997). O registro completo engloba o intervalo 450 a $65 \mathrm{Ma}$, e uma grande parte do tempo encontra-se condensado nos hiatos que separam as diversas superseqüências (Fig 1). Rio Ivaí (Caradociano-Landoveriano), Paraná (Lockoviano-Frasniano) e Gondwana I (Westfaliano-Scythiano) materializam grandes ciclos transgressivo-regressivos paleozóicos, enquanto Gondwana II (Anisiano-Noriano), Gondwana III (Neojurássico-Berriasiano) e Bauru (Aptiano-Maestrichtiano) são representados por pacotes sedimentares continentais e rochas ígneas associadas.

A Superseqüência Rio Ivaí, compreendendo as rochas sedimentares mais antigas da Bacia do Paraná, é particularmente importante no entendimento da implantação da bacia, uma vez que representa o primeiro ciclo de sedimentação fanerozóica nesta área que apoiou-se num embasamento cratônico, consolidado após os fenômenos da Orogenia Brasiliana (Almeida \& Hasui, 1983). Assim, as características inerentes ao pacote ordovício-siluriano da bacia em termos de área de ocorrência e geometria de depocentros, associados a seus atributos sedimentológicos e sua associação com rochas ígneas, permite aloumas considerações sobre a natureza e o desenvolvimento da subsidência inicial da Bacia do Paraná. Indiretamente, algumas inferências podem igualmente ser traçadas a respeito da estrutura do embasamento da sinéclise a partir da análise desses estratos basais.

Os sedimentitos Rio Ivaí ocorrem sobre amplas porções da Bacia do Paraná (Fig. 8). Sua espessura, porém, não é uniformemente distribuída, aparecendo alguns depocentros alongados segundo a orientação SW-NE. Da mesma forma, existe uma tendência de espessamento desta secão para oeste, alcançando cerca de 1.000 metros na porção paraguaia da bacia. Um padrão regional de paleocorrentes para sudoeste, medido em seus estratos mais inferiores, foi reconhecido para o pacote Rio Ivaí (Milani et al. 1995, Assine 1996). Dados de sísmica de reflexão (Marques et al 1993) mostram que a ocorrência mais espessa do pacote encontra-se confinada a um sistema de grabens SW-NE com cerca de 600 quilômetros de comprimento, estendendo-se do Paraguai à porção nordeste da bacia, já no Estado de São Paulo (Fig. 8).

$\mathrm{O}$ registro completo da Superseqüência Rio Ivaí inclui conglomerados e arenitos na base (Formação Alto Garças), diamictitos (Formação

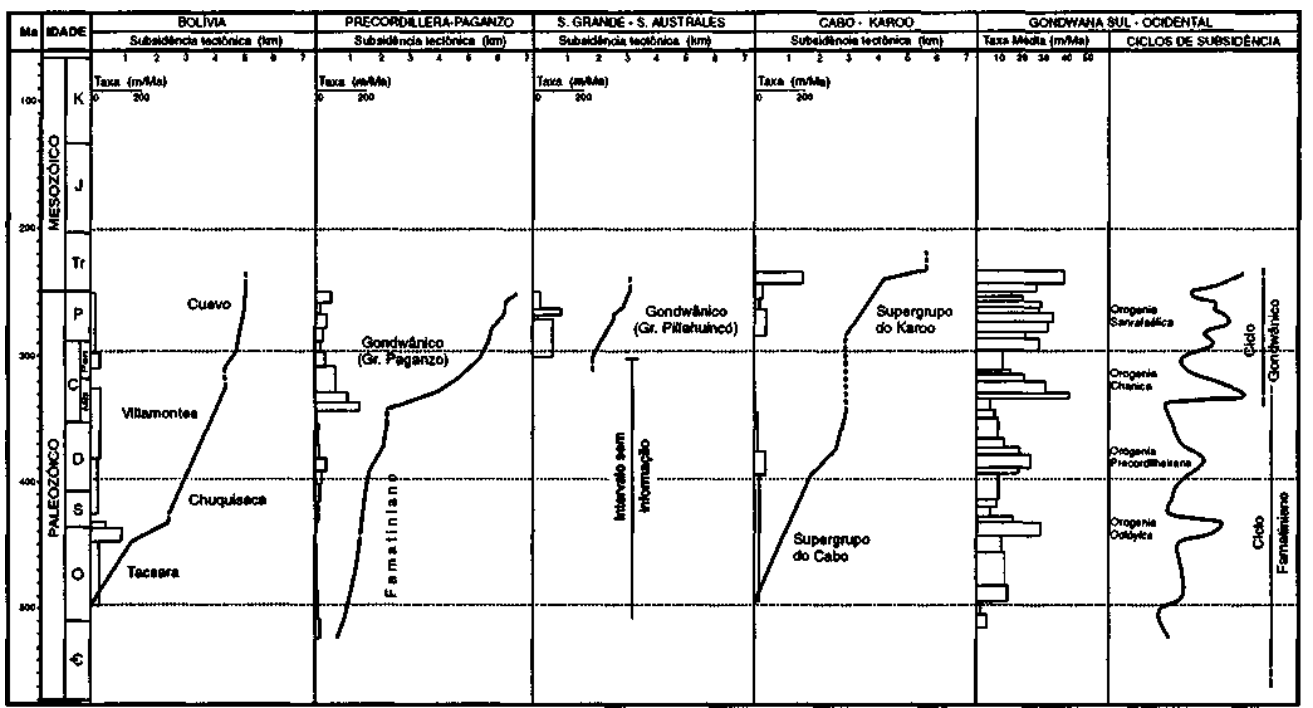

Figura 5 - Curvas de subsidência para as quatro áreas de referência no contexto dos Gondwanides, mostradas nas figuras 2 e 3. Para a Bolivia, calculou-se a curva segundo os dados estratigráficos de Gohrbandt (1993); Precordilheira-Paganzo: curva para o Ciclo Famatiniano segundo Ramos (1993), e para o Ciclo Gondwânico segundo Fernández-Seveso (1993); Sauce Grande: curva calculada segundo as informações estratigráficas de López-Gamundí et al. (1995); Cabo-Karoo: calculada a partir de dados de Veevers et al (1994) e Cole (1992). A curva calculada de taxas médias de subsidência (observar mudança de escala em relação à dos gráficos individuais), conceitualmente, mostra os principais ciclos de subsidência para a região como um todo. Escala de tempo geológico segundo Cowie \& Bassett (1989). 


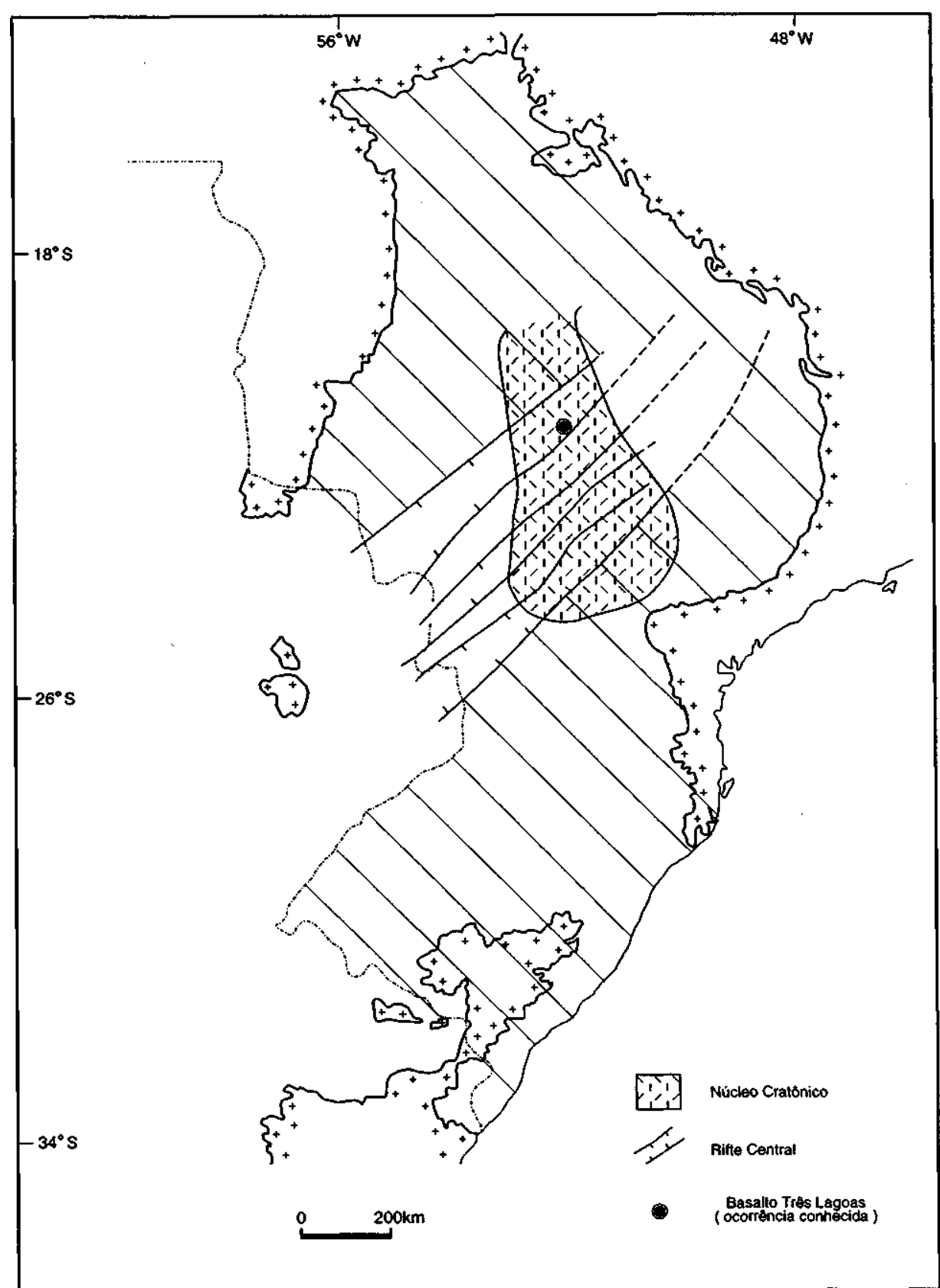

Figura 6 - Os conceitos de "núcleo cratônico" (Cordani et al. 1984) e de "rifte central" (Marques et al. 1993) da Bacia do Paraná.

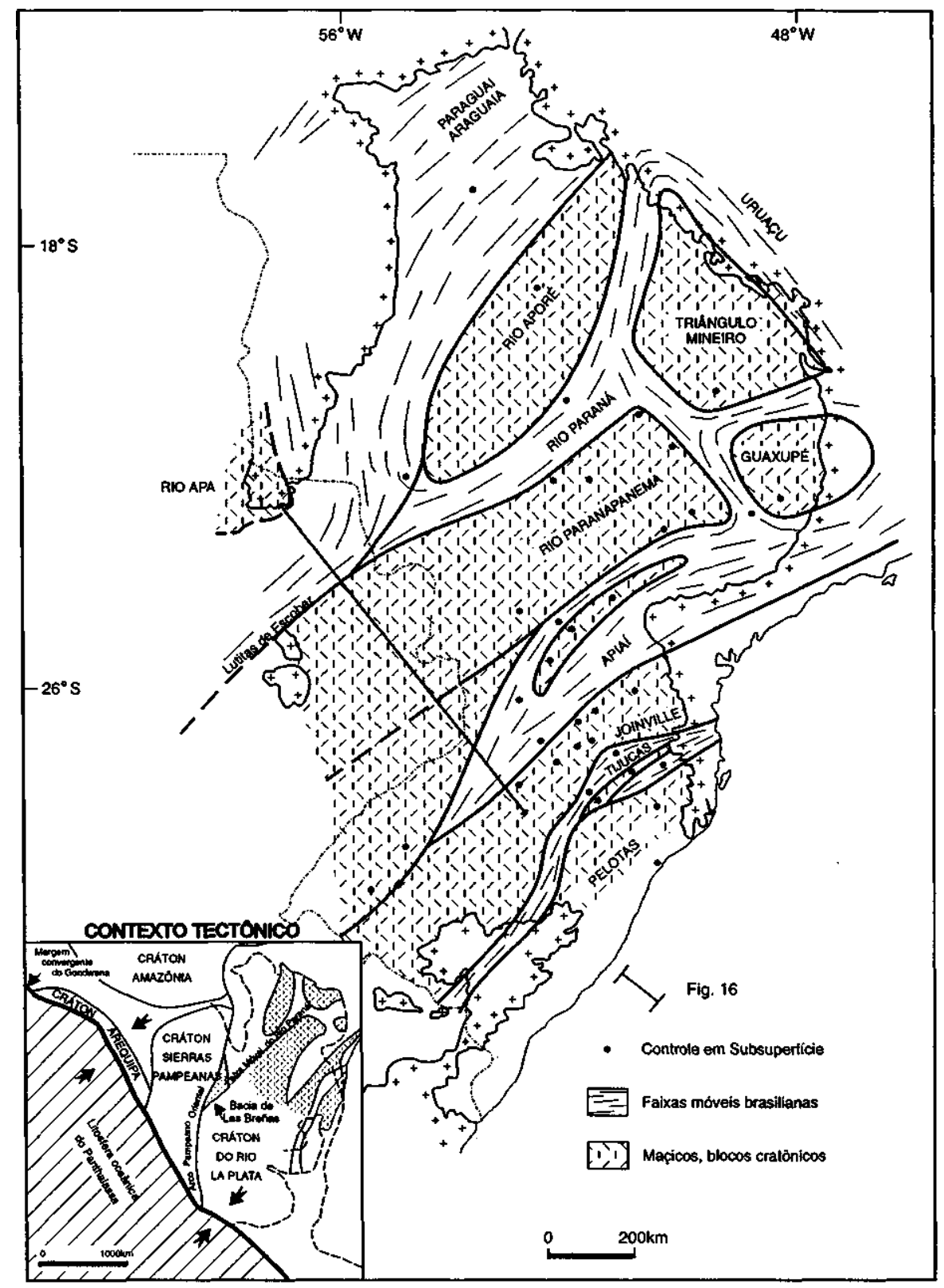

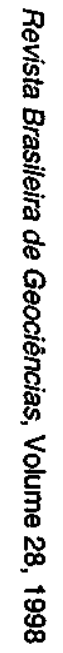

Figura 7 - Estrutura do embasamento da Bacia do Paraná. No quadro, arcabouço geotectônico regional para o domínio sul-ocidental do Gondwana, em parte baseado em Ramos \& Vujovich (1993). Setas indicam o movimento convergente entre o continente e a litosfera do Panthalassa. 
lapó) e folhelhos fossilíferos e siltitos (Formação Vila Maria), compreendendo o intervalo temporal Caradociano-Landoveriano. Os folhelhos documentam condições paleoambientais relacionadas à máxima inundação do ciclo ordovício-siluriano. A associação dos sedimentitos Rio Ivaí com rochas ígneas (basalto Três Lagoas) sugere uma tectônica sinsedimentar, provavelmente algum mecanismo de rifteamento que estaria então ligado à implantacão da Bacia do Paraná.

O topo da Superseqüência Rio Ivaí é definido por uma superficie de discordância que erodiu profundamente o pacote ordovício-siluriano e estabeleceu um vasto e regular peneplano (Fig. 9). A Superseqüência Paraná assenta sobre essa discordância, apoiada em unidades sedimentares precedentes ou diretamente no embasamento. A Superseqüência Paraná, com sua geometria tabular de ocorrência, materializa um ciclo transgressivo-regressivo completo de oscilação do nível do Panthalassa, iniciando com sedimentitos arenosos continentais a transicionais eodevonianos (Formação Furnas) recobertos em transição por sedimentitos marinhos śíltico-argilosos (Formação Ponta Grossa), datados do Emsiano ao Frasniano.

Os folhelhos do Emsiano guardam atributos sedimentológicos e características estratigráficas compatíveis com a máxima inundação do ciclo devoniano da Bacia do Paraná, correspondendo ao afogamento rápido da plataforma rasa Furnas. Informações geoquímicas (França et al 1994), igualmente, suportam a interpretação de uma seção condensada emsiana distribuída através da bacia. A Figura 10 apresenta a ocorrência da Superseqüência Paraná na bacia.

Outra superficie de discordância em ampla escala marca o limite superior do pacote devoniano. De fato, o limite Devoniano-Carbonífero constitui um marco fundamental na geologia do Gondwana (López-Gamundí \& Rossello 1993), representado na Bacia do Paraná por uma lacuna que abarca cerca de $55 \mathrm{Ma}$ conhecida como "discordância pré-Itararé" ou "discordância infra-Pensilvaniano" (Milani 1997). A mesma superfície de discordância apresenta grande angularidade naquelas porçōes da margem do Gondwana diretamente afetadas pela Orogenia Chánica, tais como as bacias do oeste argentino e a bacia de Sauce Grande. Fatores climáticos, entretanto, contribuíram certamente ao aparecimento da ampla lacuna de $55 \mathrm{Ma}$. A presença e

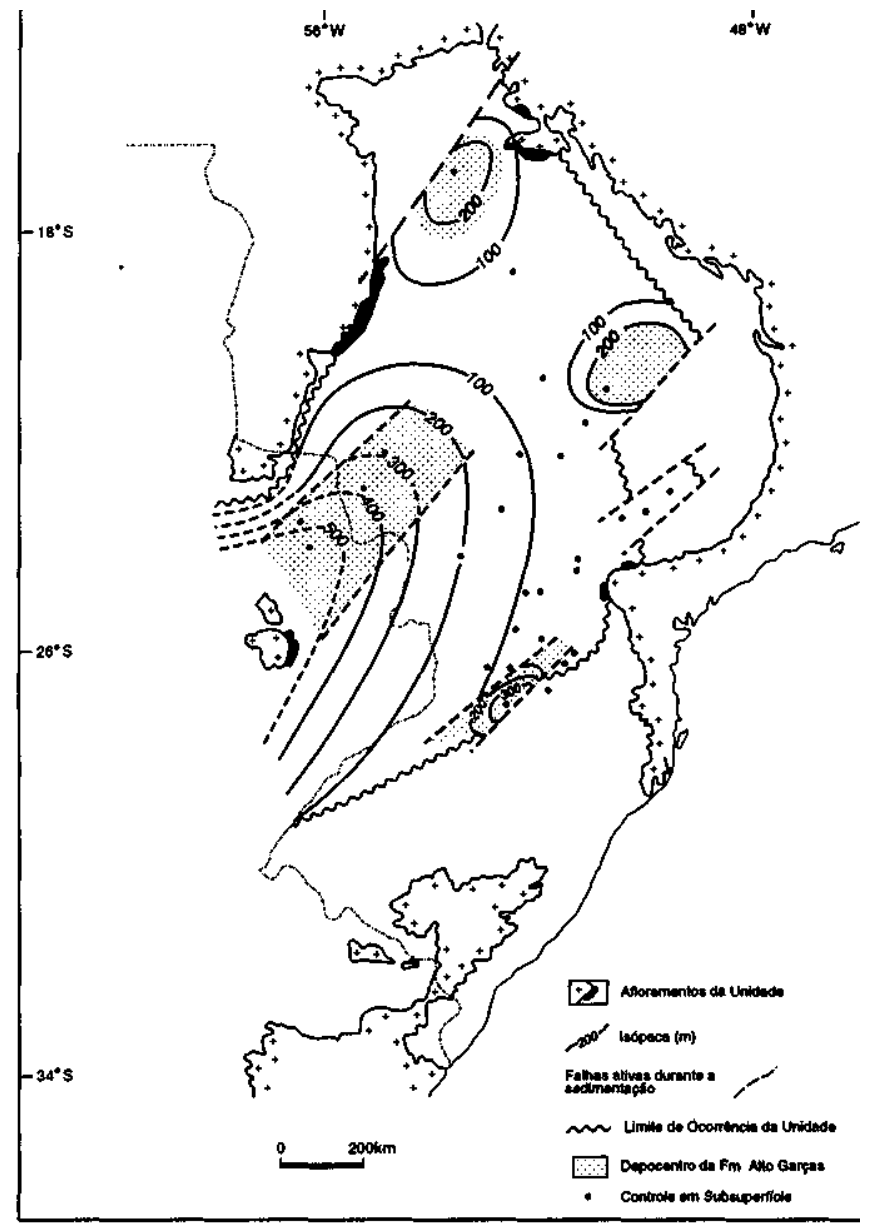

Figura 8 - Mapa de isópacas da Superseqüência Rio Ivaí. movimentações de geleiras relacionadas à grande glaciação gondwânica, cujo clímax deu-se durante o Mississipiano, forneceram importantes mecanismos de erosão e constituíram-se em obstáculos efetivos ao transporte e à acumulação sedimentar.

A Superseqüência Gondwana I (Fig. 11) sucedeu ao ápice das condições glaciais. A sedimentação foi retomada com o degelo (Eyles et al 1993), e um intenso afluxo sedimentar então teve lugar, proveniente das áreas agora expostas. $\mathrm{O}$ degelo patrocinou mecanismos de transporte e deposição em que fluxos de massa e ressedimentação foram muito importantes, retrabalhando fortemente o substrato e definindo um estilo muito particular para a secão westfaliana-sakmariana da Bacia do Paraná. O pacote diretamente ligado à fase de degelo da calota gondwânica, com 1.500 metros de espessura máxima e conhecido como Grupo Itararé (Formação Aquidauana na porção norte da bacia) é constituído dominantemente por diamictitos intercalados a arenitos, com elementos tanto glacioterrestres quanto glaciomarinhos. O pacote glaciogênico apoia-se em onlap de norte para sul (Fig. 12) sobre a discordẩncia infra-Pensilvaniano, estendendo-se sobre áreas progressivamente mais amplas. No Eopermiano, a sedimentação alcanca a porcão meridional da bacia, até então exposta à erosão.

Uma importante fase de rearranjo da geometria da bacia viria a seguir. O sentido regional de onlap das unidades sedimentares, um indicativo seguro de paleogradientes da bacia de sedimentação, foi subitamente invertido; o padrão de norte para sul, dominante durante toda a sedimentação Itararé, é sucedido por uma distribuição em onlap de sul para norte quando da acumulacão do Grupo Guatá e equivalentes (Fig. 12). Condiçôes de máximo paleobatimétrico para a Supersequiência Gondwana I estão documentados na Formação Palermo, ao início do Neopermiano. Acima, uma possante secão regressiva com até 1.400 metros de espessura (Grupo Passa Dois) foi acomodada por um ciclo de subsidência renovada do embasamento, culminando nos depósitos eólicos eotriássicos (formações Sanga do Cabral e Pirambóia).

Acompanhando a deformação da margem gondwânica, do Meso a Neopermiano (Cobbold et al 1992), teve lugar uma progressiva e irreversível continentalização dos sistemas deposicionais na Bacia do Paraná, registrada na porção terminal da Superseqüência Gondwana I (Formação Rio do Rasto). Desertos arenosos cobriram completamente a bacia e regiões vizinhas durante o Neojurássico (Formação Botucatu), seguidos pelas lavas eocretáceas da Formação Serra Geral.

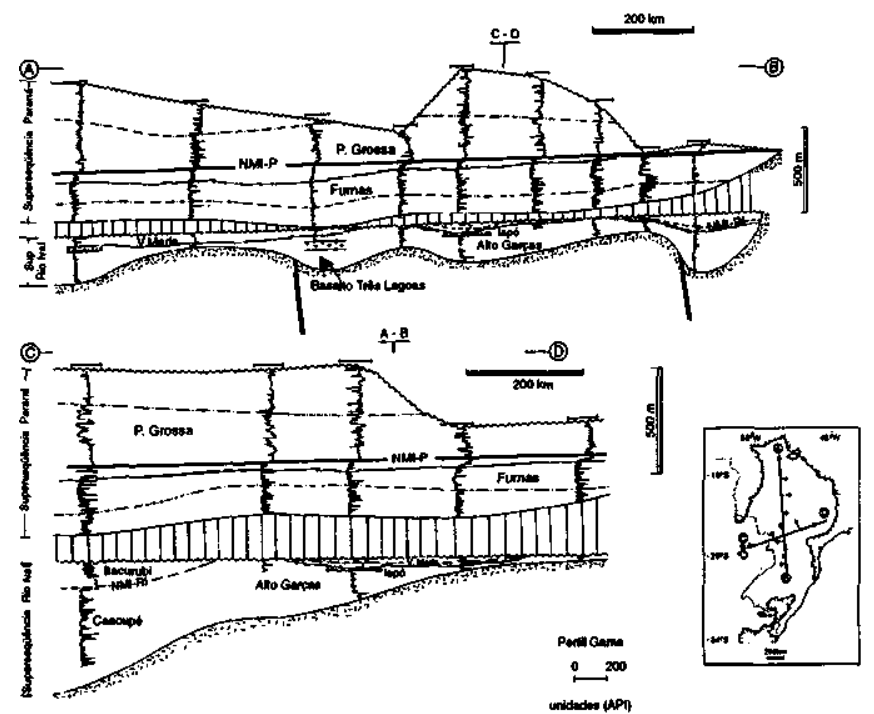

Figura 9 - Correlação de dados de poços ilustrando a ocorrência das superseqüências Rio Ivaí (ordovício-siluriana) e Paraná (devoniana) da Bacia do Paraná. Observar o contraste na geometria de ocorrência de cada uma delas, com uma distribuição irregular no pacote inferior, provavelmente controlada por descontinuidades antigas do embasamento; a unidade superior, embora tendo seu topo sido recortado durante o Mississipiano, exibe geometria tabular, e ambas acunham no sentido sul Na seção $C-D$, observe o espessamento das duas unidades no sentido oeste, principalmente a mais antiga, refletindo a configuração de depressão aberta para o Panthalassa assumida pela Bacia do Paraná em seus estágios iniciais de desenvolvimento. NMIRI e NMI-P indicam os eventos de máxima inundação durante a acumulação de cada uma das superseqüências. 
Subsidência e acumulação sedimentar na Bacia do Paraná tiveram um último evento no Neocretáceo com a acomodação da Superseqüência Bauru, um delgado pacote de sedimentitos continentais areno-conglomeráticos.

Análise de subsidência Padrões específicos de subsidência podem ser observados em bacias relacionadas a distintos contextos geotectônicos (Williams 1995). A despeito de particularidades inerentes a cada caso, que podem conduzir a combinações diversas de processos formadores de bacias, os mecanismos básicos de subsidência são ou ligados ao resfriamento da litosfera ou à flexura por sobrecarga tectônica. Exemplos de regiões que subsidem caracteristicamente por resfriamento da litosfera são as margens continentais do tipo Atlântico, enquanto a flexura litosférica por sobrecarga tectônica manifesta-se dominantemente nas faixas de antepaís adjacentes a cinturões orogênicos. Bacias intracratônicas são feições intrigantes sob o ponto de vista de seus mecanismos de subsidência, e um modelo abrangente e consolidado para explicá-las satisfatoriamente ainda não existe. Este trabalho é uma tentativa de alcançar tal entendimento para o caso da Bacia do Paraná

Grandes dimensões, associadas a um perfil em rampa de mergulho suave e uma história de sedimentação marcada por múltiplos episódios de acumulação e subsequente erosão regional de pacotes rochosos constituem os ingredientes básicos do cenário sedimentar intracratônico. Este é o caso da Bacia do Paraná, cuja história de subsidência pode ser dividida em fases, correspondentes ao intervalo temporal documentado em suas diversas superseqüências (Fig. 13).

A fase de subsidência ordovício-siluriana não pode ser adequadamente avaliada em função do pobre controle bioestratigráfico de sua seção dominantemente arenosa. A geometria da Superseqüência Rio Ivaí, definindo depocentros estreitos, alongados segundo a direção SW-NE de zonas de fraqueza do substrato da bacia, e a associação dessa sedimentação com rochas ígneas básicas, permite a especulação de algum tipo de rifteamento como o mecanismo inicial de subsidência da sinéclise.

A fase devoniana de subsidência na Bacia do Paraná iniciou com taxas pouco pronunciadas e um substrato plano, o que também parece significar o conjunto de características sedimentologico-estratigráficas da Formação Furnas. Esse pacote arenoso exibe uma geometria tabular e uma impressionante constância em suas características de espessura e atributos sedimentares através da bacia. No Emsiano, implantou-se um padrão de subsidência acelerada, conduzindo rapidamente às condições de máxima inundação marinha, o que está documentado nos folhelhos laminados, radioativos, que comparecem na porção basal da Formação Ponta Grossa. Sedimentação argilosa pontuada por progradaçốes arenosas desenvolveu-se até o Frasniano.

Após a grande lacuna mississipiana, a sedimentação foi retomada na Bacia do Paraná no Westfaliano, prolongando-se até o Eotriássico. Esta longa fase de subsidência e acomodação sedimentar inclui alguns ciclos menores. $\mathrm{O}$ rearranjo na geometria da bacia que sucedeu à sedimentação Itararé é expresso nas curvas de subsidência por um intervalo com taxas decrescentes, durante o Eopermiano. Em torno do limite Eo/Neopermiano, uma brusca quebra no estilo de subsidência é percebida nos gráficos (Fig. 13), com a entrada de um ciclo de subsidência acelerada que se prolongaria até o final da acumulação da Superseqüência Gondwana I, já no Eotriássico.

DISCUSSÃO A margem meridional do Gondwana constituiu um vasto domínio de sedimentação adjacente ao Panthalassa durante o Paleozóico. A persistência de uma movimentação convergente entre o paleocontinente e a placa oceânica, com a ocasional colisão de terrenos alóctones, desenhou um complexo quadro de orógenos e depocentros relacionados à margem ativa e diretamente ligados à dinâmica de tal contexto geotectônico. Variações eustáticas do nível do mar (Vail et ai 1977, Hallam 1984) certamente também deixaram impressa sua assinatura no registro estratigráfico dessa região. A sedimentação de natureza marinha, dominante junto à margem do paleocontinente, avançou sobre o interior cratônico do Gondwana; o mecanismo pelo qual estratos marinhos acumulam-se e são preservados nas bacias intracratônicas é um ponto fundamental na discussão que segue.

Se uma bacia sedimentar implantar-se na porção central de um continente (como por exemplo a Bacia do Pantanal, no centro da América do Sul), aquele será um sítio de sedimentação de natureza não marinha. Entretanto, a marcante presenca de pacotes marinhos nas bacias paleozóicas interiores requer efetivas comunicações do contexto intraplaca ao oceano durante alguns intervalos de tempo de sua história evolutiva. Duas linhas de pesquisa preocupam-se com estas questões; Sloss (1963) estudou a distribuição de pacotes sedimentares sobre o continente norte-americano e reconheceu, em seu arcabouco de "sequências cratônicas" separadas por "discordâncias interregionais", uma estreita relação entre os domínios do interior continental (cráton) e das margens orogênicas (geossinclinais). As conclusões de Sloss foram que a acumulação de sedimentos no interior cratônico e sua remocão erosiva foram controlados por flutuações epirogenéticas dos continentes. Segundo tal raciocínio, a área alcançada a cada momento pela sedimentacão marinha teria sido uma função de transgressões e regressões tectonicamente induzidas. O diagrama de Sloss (Fig. 14), ilustrando a distribuição das seis grandes sequências do interior cratônico da América do Norte, tornou-se um clássico na bibliografia estratigráfica, e foi seguido por pesquisadores em outros continentes (Soares et al. 1978). Sloss (1972) também reconheceu um arcabouco similar de sequências separadas por discordâncias na plataforma da Rússia, e a correlação global da epirogênese tornou-se então um paradigma. Por seu turno, Johnson (1971) sugeriu a existência de um relacionamento entre os ciclos transgressivo-regressivos documentados nas "sequências de Sloss" e o desenvolvimento dos principais períodos orogênicos no continente norte-americano.

Entretanto, se a proposta de Sloss (1963) for comparada a um diagrama análogo desenhado para a América do Sul (Fig. 14), aparece uma notável dissonância entre as duas regiões em termos do registro estratigráfico documentado em seus domínios cratônicos. Pontos de coincidência acontecem apenas eventualmente, sugerindo que a amplitude temporal das unidades preservadas em cada bloco continental foi controlada por algum tipo de fator local. Este parece ser um forte argumento contra a extrapolação das "sequências de Sloss" além dos limites da América do Norte.

Um outro grupo de cientistas assumiu a eustasia de Suess (1906) como ferramenta para estudos estratigráficos. Vail et al (1977) atribuíram as invasões de sequências marinhas sobre os continentes a oscilações de grande amplitude do nível do mar, sendo a tectônica, como mecanismo de controle do registro estratigráfico, por eles relegada a um plano secundário. A "curva de Vail", compilada a partir de informaç̃es de uma série de bacias através do mundo, foi publicada com o intuito de tornar-se uma referência para os ciclos transgressivoregressivos documentados sobre os cinco continentes. A América do Sul e, por conseguinte, a Bacia do Paraná, deveriam incluir-se nesse esquema "global" de correlação estratigráfíca. Mas este não parece ser o caso.

Comparando-se o registro estratigráfico da Bacia do Paraná à curva de Vail (Fig. 15), percebe-se que os melhores picos de "correlação global", definidos por aqueles momentos de máxima inundação marinha, situam-se temporalmente no Neossiluriano, Eocarbonífero e Eopermiano. O registro de tais "altos eustáticos" não se fazem presentes na Bacia do Paraná. Níveis de máxima inundação de caráter "local" foram documentados na Bacia do Paraná no Eossiluriano, Eodevoniano e Neopermiano, refletindo variações do nível relativo do mar inerentes a essa porção do continente que provavelmente responderam a uma combinação entre a história de subsidência particular da Bacia do Paraná e as oscilações eustáticas (absolutas) do nível do mar.

Notar que, neste trabalho, os principais fatores de controle do registro estratigráfico, por um lado a subsidência do embasamento de uma região específica do planeta, neste caso o domínio sul-ocidental do Gondwana, e por outro as variações eustáticas do nível do mar, foram consideradas variáveis completamente independentes. Em outras palavras, se fosse possível admitir que a subsidência de uma bacia ocorresse segundo uma taxa constante, a ciclicidade observada em seu arcabouço estratigráfico seria resultado exclusivo das oscilações eustáticas. Desta forma, para o caso de uma bacia em particular, a variação do nível "global" do mar foi considerada um fator alóctone, produto de uma combinação de fenómenos em escala planetária. Originada fora dos limites daquela bacia específica, a variação eustática do nível do mar influi em seu registro estratigráfico de modo independente a sua história tectônica particular.

No desenvolvimento da Bacia do Paraná, a geodinâmica do Gondwana sul-ocidental parece ter sido de grande influência. A dissipação intraplaca de esforços ao longo de antigas zonas de fraqueza e a propagação no sentido do antepaís para o interior cratônico da flexura litosférica por sobrecarga tectônica estão entre os mecanismos admitidos como controladores primordiais da subsidência e da assinatura estratigráfica nessa bacia interior (Milani 1997).

\section{A Orogenia Oclóyica e a implantação da Bacia do Paraná}

O pacote mais antigo da Bacia do Paraná, o da Formação Alto Garças, é datado como Neo-Ordoviciano e sua ocorrência é controlada por zonas de fraqueza do embasamento de orientação SW-NE (Fig. 8). Numa escala regional (Fig. 7), este conjunto de descontinuidades 
SW-NE prossegue através do Paraguai e vai encontrar a Faixa Pampeana Oriental (Ramos \& Vujovich 1993) na Argentina. Este arcabouço de descontinuidades em ampla escala foi muito importante no

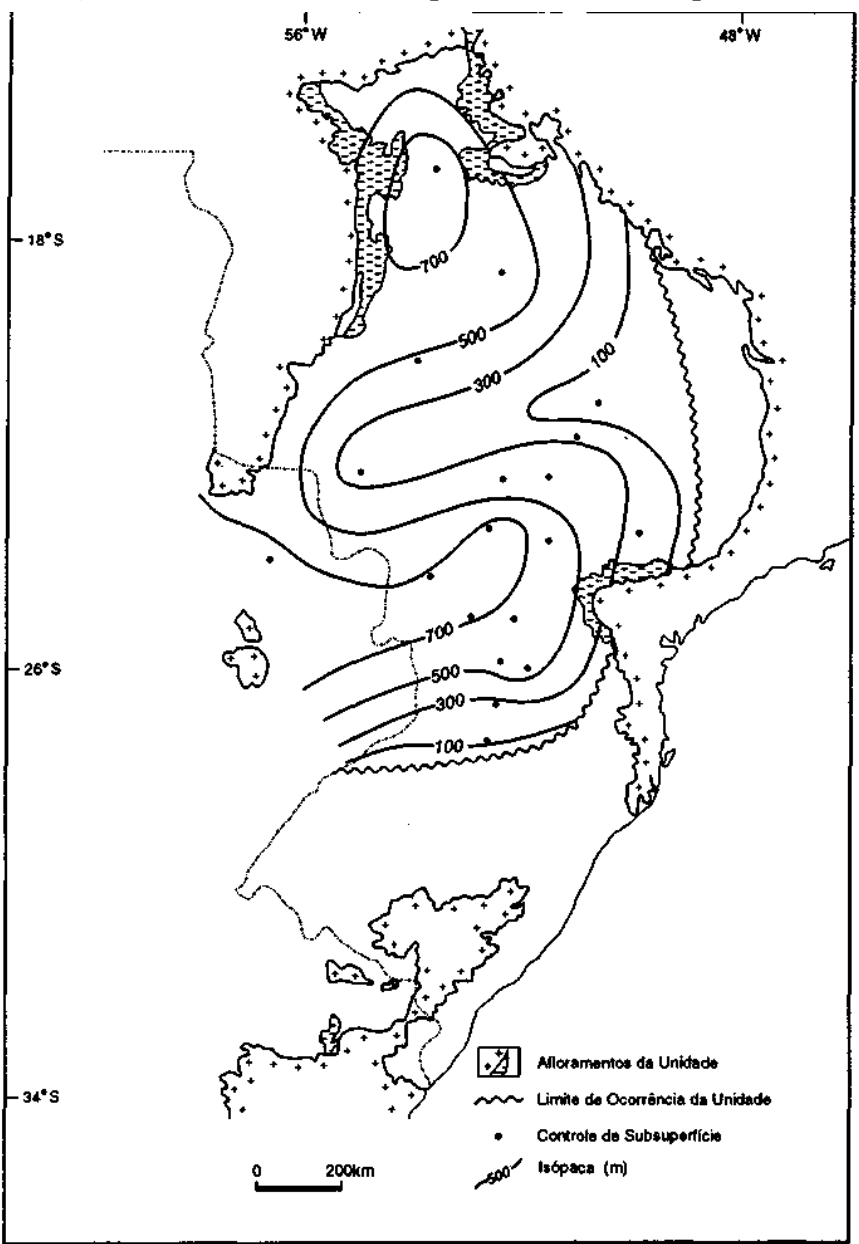

Figure 10 - Mapa de isópacas da Superseqüência Paraná.
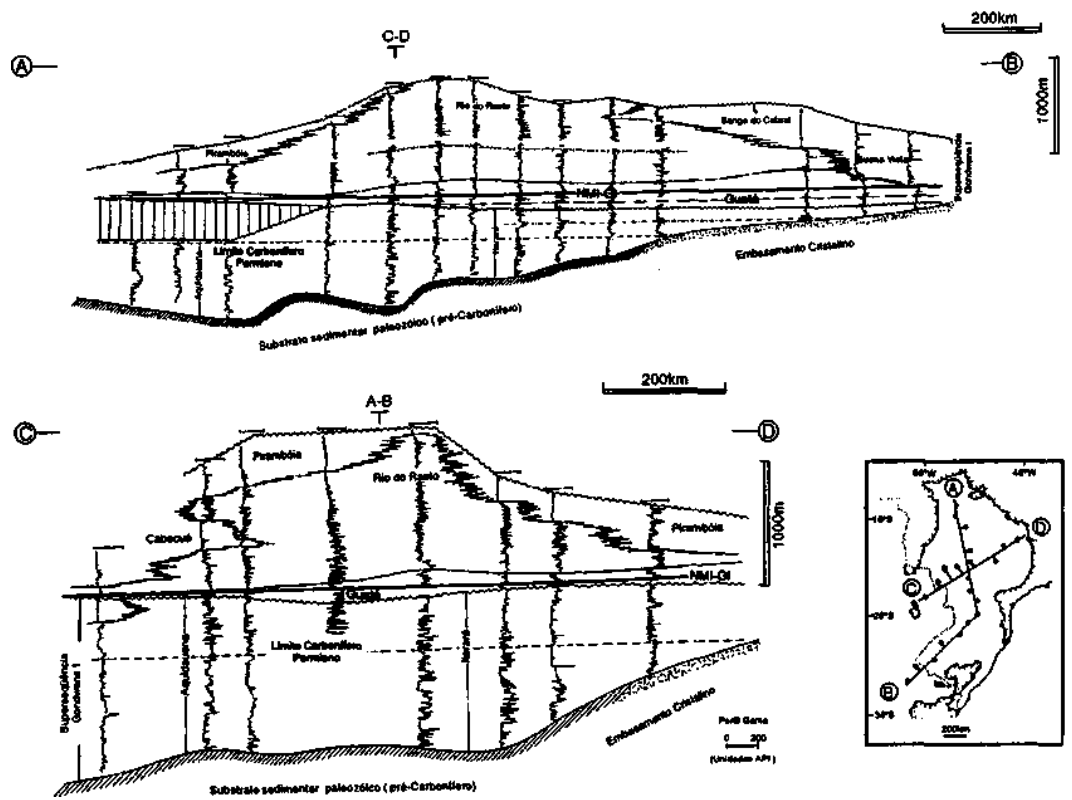

Figura 12 - Correlação de dados de poços ilustrando a distribuição da Superseqüência Gondwana I (Carbonifero-Eotriássico) da Bacia do Paraná. Notar, na seção $A-B$, a inversão no sentido do onlap do pacote sedimentar, de norte para sul na seção mais inferior, e no sentido oposto para a sedimentação Guatá. Enquanto o Grupo Guatá e seus correspondentes estratigráficos acumulavam-se em onlap de sul para norte, a porção setentrional da bacia era submetida a exposição subaérea e intensa remoção erosiva. As informações na seção C-D sugerem a permanência, até o Carbonifero, da geometria de depressão aberta para oeste. Tal configuração foi modificada durante o Permiano e Triássico, com o avanço de sistemas continentais (formações Cabacuá, Pirambóia, Sanga do Cabral e Buena Vista) no sentido do lago remanescente (Formação Rio do Rasto) que ocupava a porção central da bacia. sentido de promover uma conexão mecânica entre a margem da placa seu interior. Ao longo destas feições lineares pré-existentes, esforços contraram um modo de dissiparem-se, até mesmo no remoto interior do continente. A Bacia de Las Breñas (Fig. 7) ocorre igualmente ao

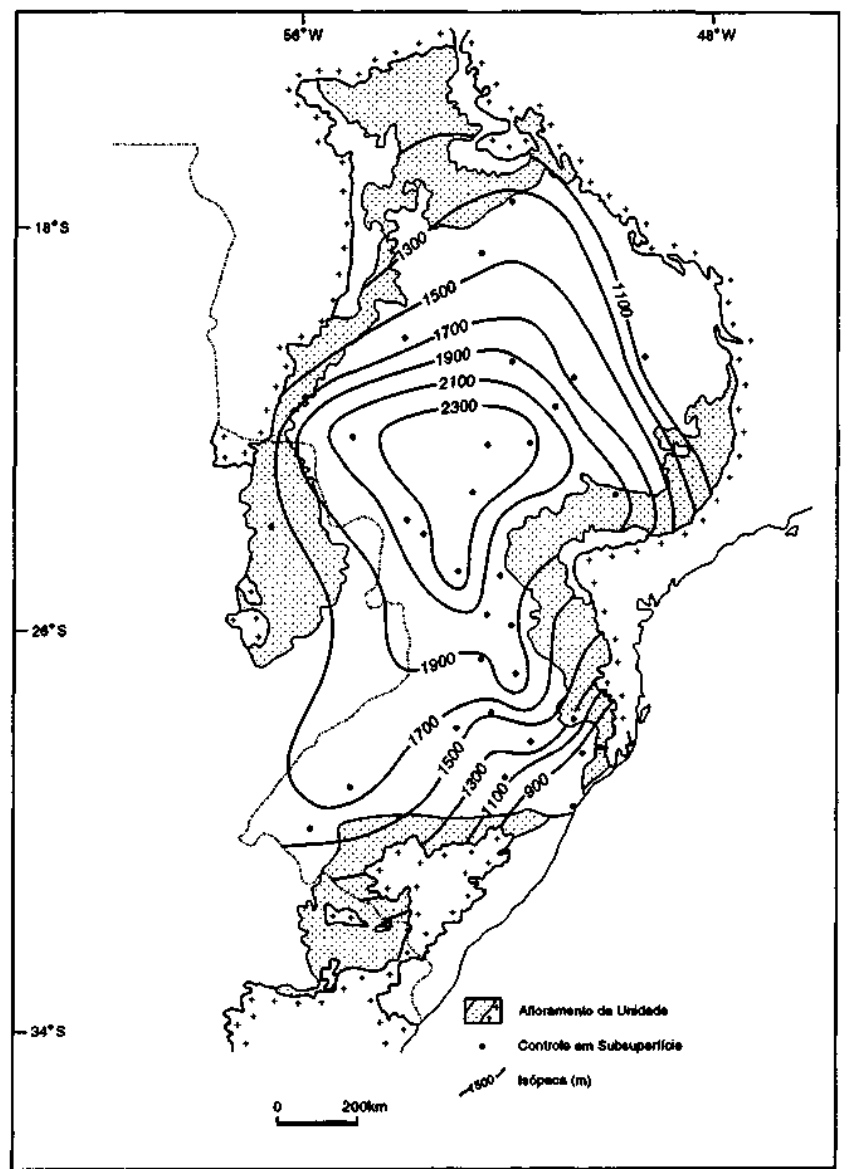

Figura 11 - Mapa de isópacas da Superseqüência Gondwana I. 


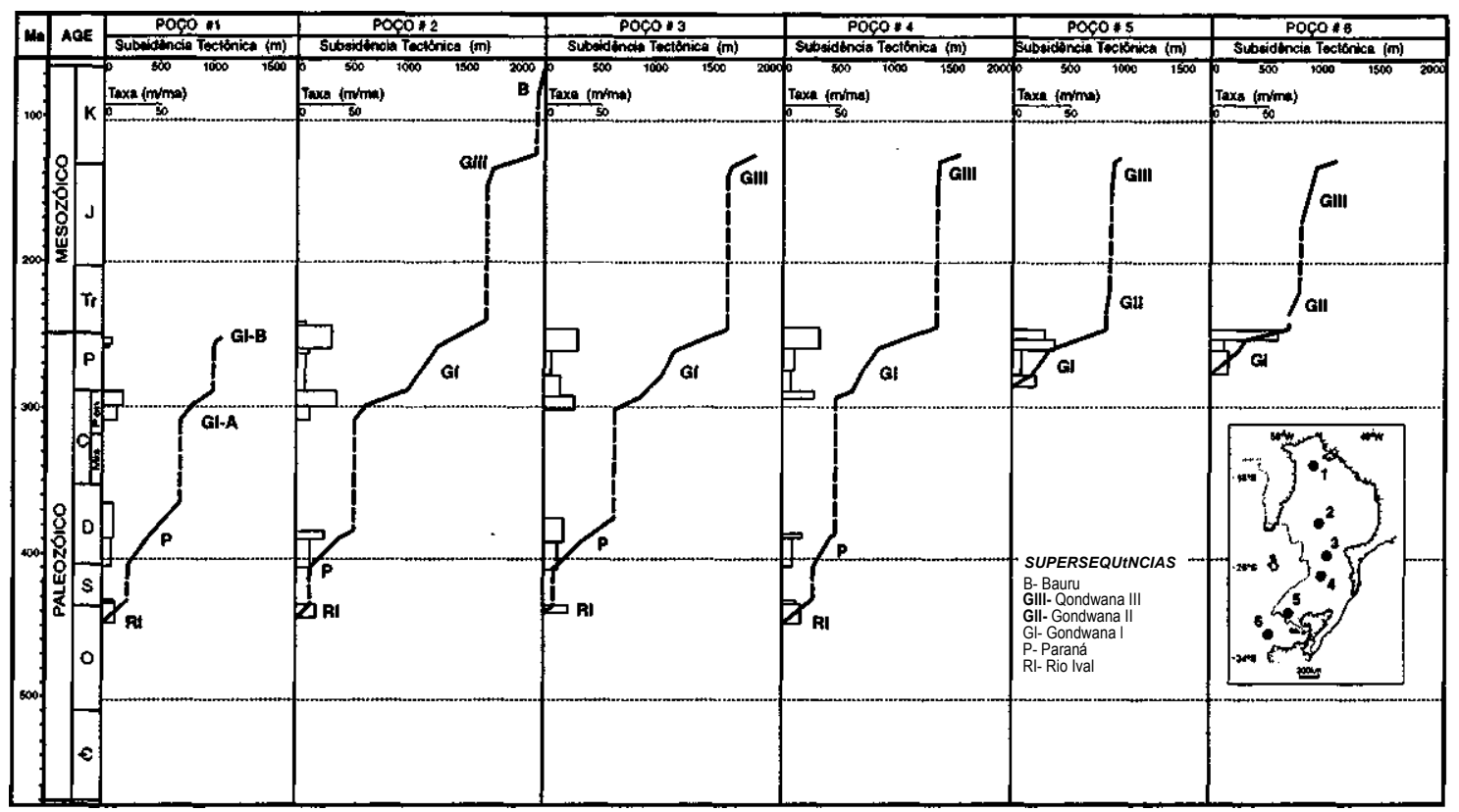

Figure 13 - Gráficos de subsidência calculados a partir de informações de seis poços da Bacia do Paraná. Escala de tempo segundo Cowie \& Bassett (1989).

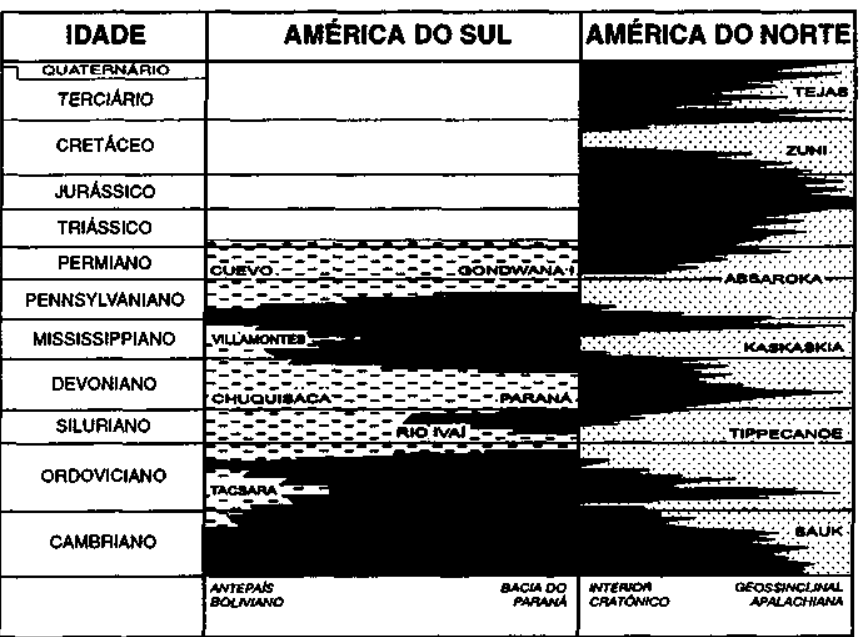

Figura 14 - Diagrama espaço-tempo comparando a distribuição de unidades estratigráficas fanerozóicas na porção oeste da América do Sul e leste da América do Norte, esta última segundo Sloss (1963). Informações da porção boliviana segundo Sempere (1995). A comparação intercontinental mostra uma conspícua dissonância entre o registro estratigráfico de cada um dessas regiões, sendo a correlação exata dos pacotes rochosos uma exceção.

longo deste trend estrutural e consiste em um graben preenchido por um pacote cambro-ordoviciano (Pezzi \& Mozetic 1989) que foi deformado por um evento compressivo pré-Siluriano, muito provavelmente durante o Meso a Neo-Ordoviciano.

No Meso a Neo-Ordoviciano o terreno Precordilheira colidiu contra o Gondwana (Ramos 1990, Astini et al. 1996). A acomodação dos esforços da Orogenia Oclóyica na região cratônica induziu a subsidência inicial da Bacia do Paraná, na forma de depocentros transtensivos alongados na direção SW-NE. A associação da sedimentação inicial da bacia, a Superseqüência Rio Ivaí, com magmatismo intraplaca sugere fortemente ter ocorrido uma reativação ordoviciana de suturas antigas do embasamento (Fig. 16), abrindo o caminho para a ascensão do basalto Três Lagoas. Da mesma forma, como já fora sugerido por Assine (1996), uma estreita correlação é observada entre a amplitude temporal do ciclo de subsidência causado pela Orogenia Oclóyica e a amplitude temporal da Superseqüência Rio Ivaí (Fig. 17), estando o momento da máxima inundação desse ciclo sedimentar, no Landoveriano, muito próximo em tempo ao clímax orogênico.

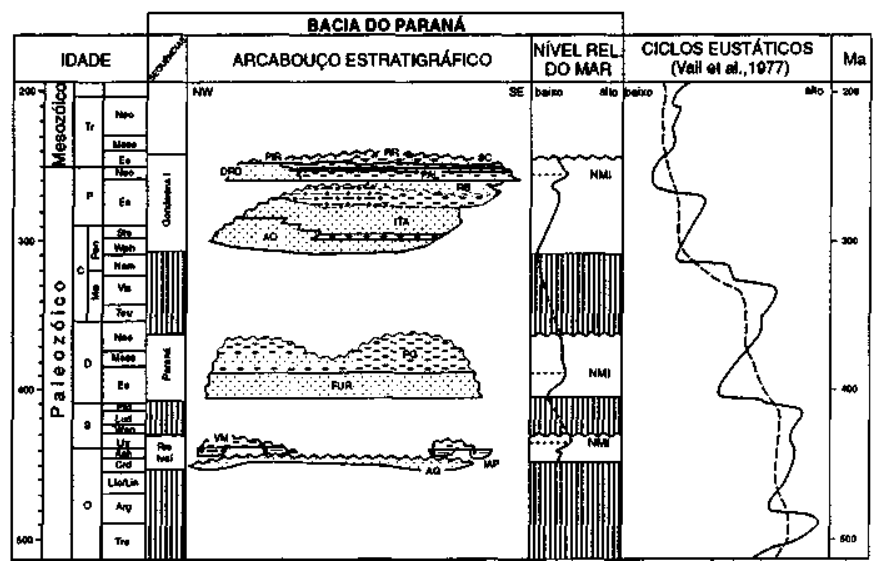

Figura 15 - O registro paleozóico marinho da Bacia do Paraná comparado à curva de Vau (Vau et al 1977). Observar que os máximos eustáticos, supostamente picos de correlação global, não estão registrados na Bacia do Paraná. Por seu turno, niveis de máxima inundação de caráter local nela se desenvolveram, como resultado de sua história de subsidência particular. Denominação das unidades litoestratigráficas: AG-Formação Alto Garças, IAP-Formação lapó, VM-Formação Vila Maria, FUR-Formação Furnas, PG-Formação Ponta Grossa, AQ-Formação Aquidauana, ITA-Grupo Itararé, RB-Formação Rio Bonito, PAL-Formação Palerma, DRD-Formação Dourados, RRFormação Rio do Rasto, PIR-Formação Pirambóia, SC-Formação Sanga do Cabral. Simbologia litológica é a usual. Escala de tempo segundo Cowie \& Bassett (1989).

A atenuação do campo de tensões da Orogenia Oclóyica foi percebida na Bacia do Paraná pelo decréscimo das taxas de subsidência ainda no Siluriano, em tempos pós-landoverianos. Embora fosse o Siluriano no seu todo um tempo de nível eustático crescente (Fig. 17), ele caracterizou-se como época de erosão na Bacia do Paraná, uma circunstância que mostra o significado da história de subsidência da bacia como mecanismo de controle de seu registro estratigráfico.

O ciclo devoniano de subsidência: flexura litosférica em ampla escala $\mathrm{O}$ registro devoniano na Bacia do Paraná inicia com a Formação Furnas, um pacote arenoso de geometria tabular acumulado sobre um amplo e estável peneplano pós-oclóyico. As condições de estabilidade foram quebradas por um ciclo de subsidência acelerada durante o Praguiano-Emsiano, neste caso patrocinado por outra fase de deformação na margem gondwânica, a Orogenia Precordilheirana 


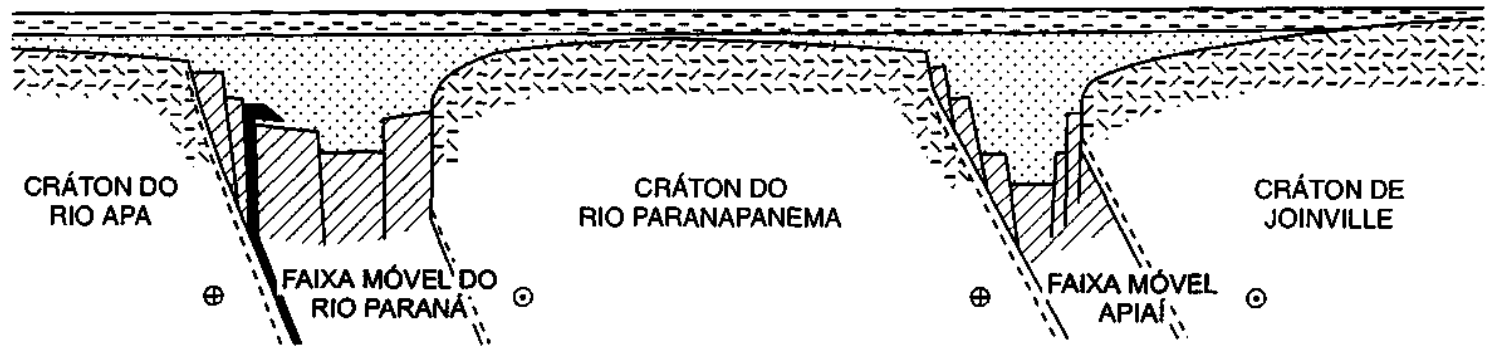

SUPERSEQOENCIA RIO IVAI

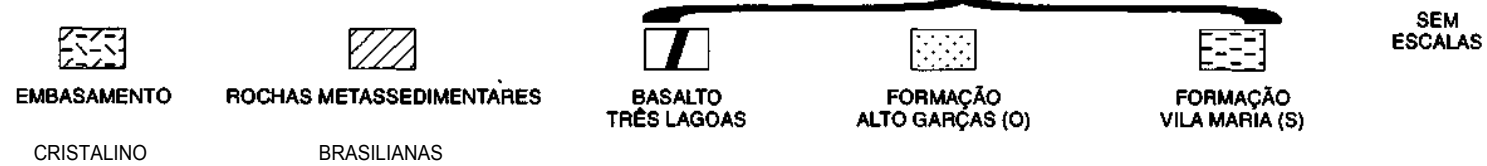

Figura 16 - Diagrama esquemático ilustrando o controle tectônico sobre a sedimentação durante a acumulação do pacote ordovício-siluriano da Bacia do Paraná. Observar o desenvolvimento de grabens transtensivos ao longo de suturas do embasamento. Localização na Fig. 7.

(Fig. 17). A aceleração da subsidência conduziu a um rápido afogamento dos sistemas transicionais da Formação Furnas e de sua correlata no oeste argentino, a Formação Santa Rosa. À semelhança do observado para a Superseqüência Rio Ivaí, o nível de máxima inundação da Superseqüência Paraná, de idade Emsiana, correlacionase muito bem ao tempo das maiores taxas de subsidência no antepaís, relacionadas agora ao clímax da Orogenia Precordilheirana.

Uma questãoo emerge da observação de que os domínios de antepaís e intracratônico experimentaram episódios sincronizados de subsidência e acumulação sedimentar; ela diz respeito à presença e ao papel do bulge periférico (Beaumont 1981), um elemento ligado à intrínseca rigidez litosférica durante a flexura e frequentemente invocado como barreira paleofisiográfica e limite entre tais domínios de subsidência. Se uma feição estrutural positiva emergisse entre as duas regiões subsidentes, este seria um importante elemento controlador de fácies sedimentares. Na área aqui estudada, entretanto, a assinatura transgressiva-regressiva da seção devoniana foi registrada de modo síncrono em toda essa ampla região, tanto no antepaís quanto no contexto intracratônico, mostrando a inexistência de uma efetiva barreira entre os dois distintos domínios de subsidência.

Quinlan \& Beaumont (1984) estudaram um contexto similar, na margem Apalachiana da América do Norte. Em suas figuras, eles ilustram o bulge flexural como uma feição de amplitude vertical acentuada, separando marcadamente os sítios de antepaís e intracratônico. Tal configuração traria implícito que um pulso orogênico seria percebido no domínio intracratônico como um momento de regressão, uma vez que a orogenia motivaria a subida do bulge flexural, isolando o interior do continente e elevando as bordas da bacia interior. Esta relação geométrica, entretanto, parece não se aplicar adequadamente à região aqui abordada. No Devoniano do Gondwana sul-ocidental, observa-se um vínculo entre o pulso orogênico e a invasão franca das fácies marinhas no sentido do cráton, indicando transgressões tectonicamente induzidas.

Este comportamento diferenciado da litosfera gondwânica pode ter sido condicionado pela natureza dos episódios colisionais lá acontecidos; a chegada de terrenos lateralmente limitados (Fig. 18) deve ter induzido uma concentração de esforços em áreas específicas da margem ativa. Do mesmo modo, uma litosfera de elevada rigidez igualmente teria favorecido uma efetiva propagação da deformação flexural no sentido do interior continental.

A distribuição do pacote devoniano na porção sul-ocidental da América do Sul é mostrada na Figura 18. Nesta correlação regional de dados de poços entre a Bacia do Paraná e o oeste argentino, parece ser admissível o fato de que a subsidência tenha sido compartilhada entre os domínios de antepaís e intracratônico. Os gráficos de subsidência ilustram com clareza a aceleração de subsidência experimentada simultaneamente em toda a região a partir do Emsiano, permitindo a interpretação de que as condições de máxima inundação do ciclo devoniano deram-se não como resposta a uma subida eustática, mas sim como resultado de um aprofundamento rápido do substrato.

\section{Tectônica e sedimentação no Carbonífero e Permiano}

A Orogenia Chanica, do Eocarbonífero, produziu um ciclo renovado de subsidência muito bem documentado no antepaís. No oeste argentino, o ciclo Guandacol da Bacia de Paganzo, do Mississipiano,

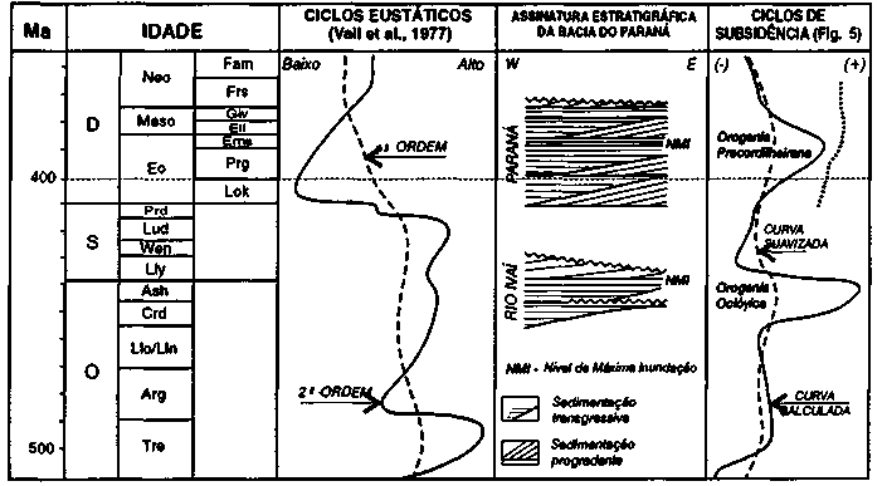

Figura 17 - Assinatura estratigráfica das superseqüencias Rio Ivaí e Paraná da Bacia do Paraná e seu relacionamento com os ciclos eustáticos de Vail e com os ciclos de subsidência do Gondwana sul-ocidental. Observe que a amplitude temporal de cada superseqüencia encontra-se confinada aos limites do ciclo de subsidência patrocinado por cada orogenia, e que os episódios de máxima inundação praticamente coincidem com o momento do ápice orogênico. A curva de taxas médias de subsidência (pontilhada), computada aritmeticamente para a Superseqüencia Paraná a partir das informações da Fig. 13, mostra um bom ajuste com o ciclo de subsidência no antepaís relacionado à Orogenia Precordilheirana. Por outro lado, não parece existir uma correspondência entre a assinatura destas superseqüencias e os altos e baixos da eustasia. Escala de tempo segundo Cowie \& Bassett (1989).

corresponde a esta fase de subsidência (Fernández-Seveso \& Tankard 1995). Na Bacia do Paraná, este foi um tempo de não-deposição basicamente em função da presença e influência dos glaciares na área da bacia de sedimentação. A acumulação sedimentar só seria retomada no Westfaliano, então sendo contínua até o Eotriássico. A influência marinha na sedimentação reduzir-se-ia progressivamente com o passar do tempo, indicando um progressivo e efetivo fechamento da bacia às incursões do Panthalassa.

Ao final do Eopermiano, a morfologia da Bacia do Paraná foi profundamente modificada (Fig. 12), fato que coincide em tempo ao clímax da Orogenia Sanrafaélica (Fig. 19). O material vulcanogênico que ocorre na seção do Permiano Inferior da Bacia do Paraná (Coutinho et al 1991) correlaciona-se ao evento Choiyoi do oeste da Argentina, onde corresponde a um vasto arco magmático calcio-alcalino distribuído no tempo entre 275 e 250 Ma (Kay et al 1989) e que deve ter-se constituído em um efetivo, e provavelmente definitivo, obstáculo ao acesso marinho sobre o Gondwana meridional (Urien et al. 1995).

Considerações finais As informações aqui manuseadas conduziram à interpretação de que existiu uma estrita correlação entre a evolução da Bacia do Paraná no interior continental do Gondwana e o regime tectônico atuante ao longo dos Gondwanides durante o Paleozóico. O substrato do Gondwana sul-ocidental reagiu por flexura 

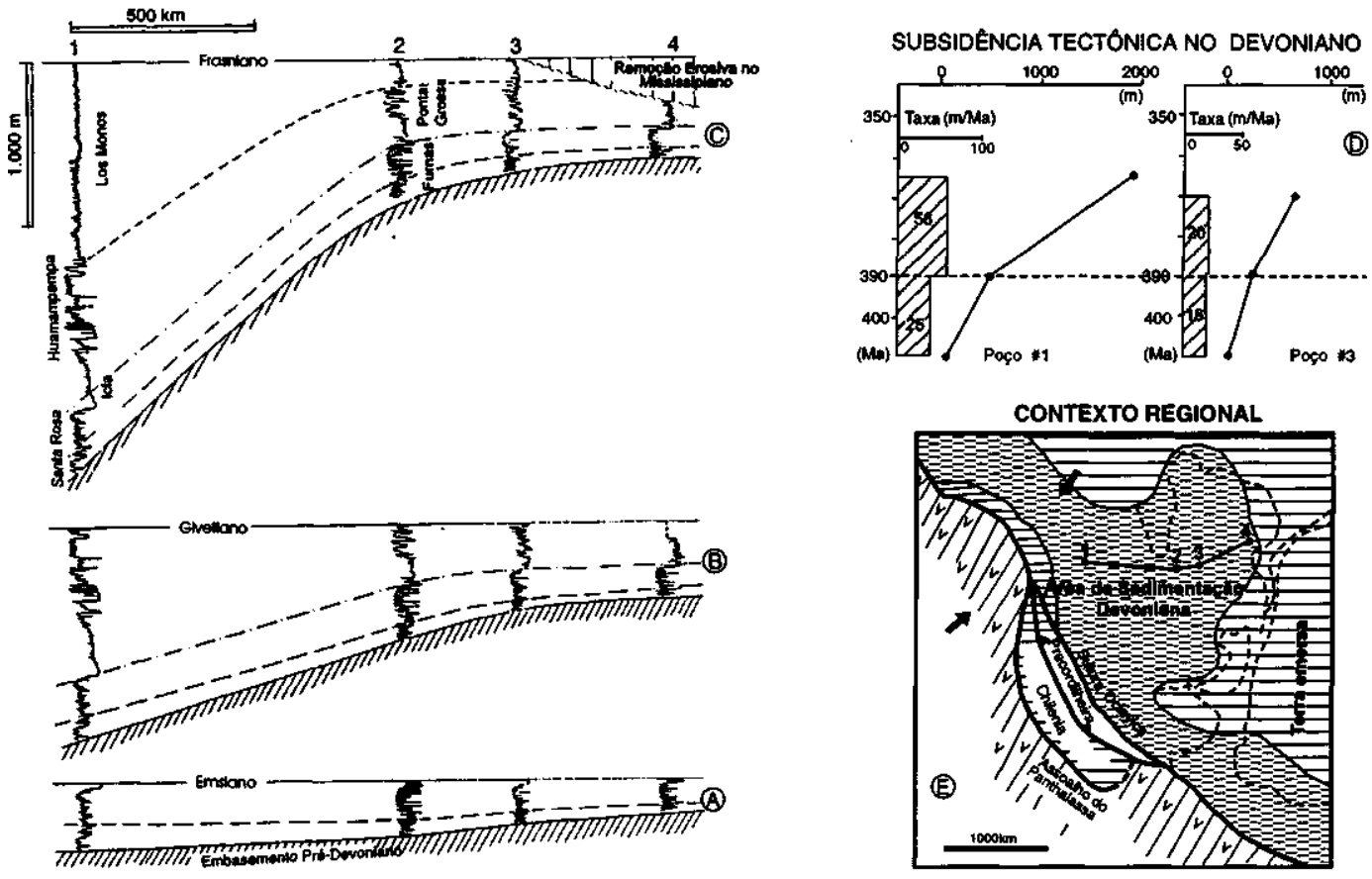

Figura 18 - Correlação regional de dados de poços mostrando a distribuição de estratos devonianos através da porção meridional da América do Sul. Idades para as unidades boliviano-argentinas são de Barrett \& Isaacson (1988), e para a Bacia do Paraná são de Melo (1988). (A) Entre o Lockoviano e o Praguiano, um substrato estabilizado favoreceu o desenvolvimento de um pacote tabular de arenitos continentais a marinho rasos (formações Santa Rosa/Furnas). O Emsiano marcou o início de um ciclo de subsidência acelerada, que conduziu (B) ao desenvolvimento das condições de máxima inundação de todo o ciclo devoniano. Os gráficos de subsidência (D) mostram a quebra tanto no antepaís quanto no domínio intracratônico, com taxas crescentes a partir do Emsiano, e este evento de aceleração da subsidência é invocado como o responsável pelo rápido afogamento de toda esta área. (C) Taxas de subsidência relativamente elevadas continuaram até o Frasniano, propelidas pelos movimentos terminais da Orogenia Precordilheirana. Reconstituições paleogeográficas/paleotectônicas em parte baseadas

em Ramos et al (1986).

sob os campos de esforços originados ao longo da margem ativa, e este fato representou um efetivo mecanismo de criação de espaço à acumulacão sedimentar no domínio intracratônico. Este mecanismo de subsidência parece refletir a propagação para o interior continental da flexura litosférica a partir da calha de antepaís, de tal sorte que a Bacia do Paraná experimentou fases de subsidência acelerada que correlacionam-se estreitamente às do domínio de antepaís adjacente. Como resultado, a amplitude temporal das superseqüências da Bacia do Paraná está claramente confinada aos limites temporais dos diferentes ciclos de subsidência patrocinados pelas orogenias paleozóicas da margem do Gondwana. As assinaturas estratigráficas das várias superseqüências, em termos de ciclos trasgressivo-regressivos, da mesma forma apresentam uma estreita correlação aos ciclos de subsidência do Gondwana sul-ocidental.

A correlação global de eventos estratigráficos proposta na curva de Vail ou as sequências cratônicas de Sloss não fornecem os meios para elucidar de maneira satisfatória a construção do arcabouço estratigráfico da Bacia do Paraná. Outrossim, ele parece muito mais um produto direto da história de subsidência da bacia, história essa que se deu em marcante sintonia com o desenvolvimento tectônico do Gondwana sul-ocidental.

Agradecimentos Este trabalho constitui síntese da Tese de Doutorado de E. J. Milani (UFRGS, 1997), que contou com a orientação do Prof. Victor A. Ramos no tocante à análise tectônica regional. Os autores agradecem à Petróleo Brasileiro S. A. pela liberação dos dados de sua propriedade. Peter Szatmari, Pedro V. Zalán e César Cainelli revisaram versões preliminares deste artigo, o que em muito contribuiu ao seu aprimoramento. Os autores agradecem igualmente ao revisor anónimo da RBG por seus pertinentes comentários.

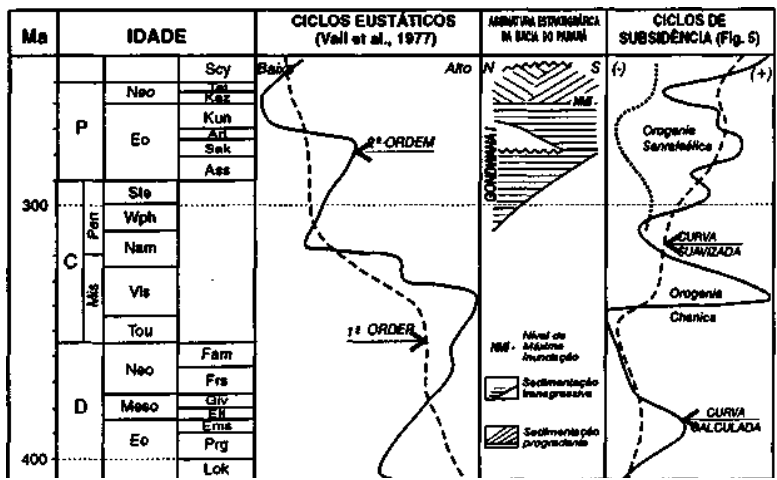

Figura 19 - Assinatura estratigráfica da Superseqüência Gondwana I da Bacia do Paraná e seu relacionamento com a curva de Vail e com os ciclos de subsidencia do Gondwana sul-ocidental (Milani 1997). Curva pontilhada representa as taxas médias de subsidência em escala de bacia, obtida aritmeticamente a partir dos dados da Fig. 13. Observar a coincidencia existente entre as taxas mais elevadas de subsidência no domínio do antepaís do Gondwana sul-ocidental, registradas durante o Eopermiano e relacionadas à Orogenia Sanrafaélica, e o rearranjo estrutural experimentado pelo substrato da Bacia do Paraná, o que é indicado pelas taxas decrescentes na curva pontilhada. Seguiu-se a inversão no sentido do onlap sedimentar e um renovado ciclo de subsidência acelerada, já no Permiano terminal. Escala de tempo segundo Cowie \& Bassett (1989).

\section{Referências}

Almeida, F.F.M. \& Hasui, Y. 1983. O Pré-Cambriano do Brasil. Edgard Blücher, 378 p.

Andreis, R.R.; Ifliguez, A.M.; Lluch, J.L.; Rodrfguez, S. 1989. Cuenca paleozóica de Ventania, Sierras Australcs, Província de Buenos Aires. In: G. A. Chebli \& L. A. Spallctii (cds.) Cuencas sedimentarias argentinas. Tucuman: Universidad Nacional, Serie Correlacion Geológica, n. 6, p. 265-298.
Assine, M.L. 1996. Aspectos da estratigrafia das sequências pré- carboniferas da Bacia do Paraná no Brasil. Instituto de Geociências, Universidade de São Paulo, Tese de Doutoramento, $207 \mathrm{p}$.

Astini, R.A. 1996. Las fases diastróficas dei Paleozóico Médio en Ia Precordillera del oeste argentino -evidencias estratigráficas. In: Congreso Geológico Argentino y Congreso de Exploración de Hidrocarburos, 13/3, 1996. Actas... Buenos Aires, Asociación Geológica Argentina y Instituto Argentino del Petróleo y del Gás, v. 5, p. 509-526. 
Astini, R.A.; Benedetto, J.L.; Vaccari, N.E. 1995. The early Paleozoic evolution of the Argentine Precordillera as a Laurentian rifted, drifted, and collided terrane - a geodynamic model. Geológical Society of America Bulletin, 107(3):253-273.

Astini, R.A.; Ramos, V.A.; Benedetto, J.L.; Vaccari, N.E.; Canas, F.L. 1996. La Precordillera: un terreno exótico a Gondwana. In: Congreso Geológico Argentino y Congreso de Exploración de Hidrocarburos, 13/3, 1996. Actas... Buenos Aires, AGA/IAPG, v. 5, p. 293-324.

Bahlburg, H. \& Breitkreuz, C. 1991. Paleozoic evolution of active margin basins in the Southern Central Andes (Northwestern Argentina and Northern Chile). Journal of South American Earth Sciences, 4(3): 171 -188

Barrett, S.F. \& Isaacson, P.E. 1988. Devonian paleogeography of South America. In: N. J.

Mcmillan; A. F. Embry; D. J. Glass (eds.) Devonian of the world. Calgary: Canadian

Society of Petroleum Geologists Memoir 14, v. I, p. 655-667.

Beaumont, C. 1981. Foreland basins. Geophysical Journal of the Royal Astronomical Society, 55:291-329.

Borrello, A.V. 1965. Sobre Ia presencia del Cámbrico inferior olenellidiano en Ia Sierra de Zonda, Precordillera de San Juan. Ameghiniana III, 10:313-318

Cobbold, P.R.; Gapais, D.; Rossello, E.A.; Milani, E.J.; Szatmari, P. 1992. Permo-Triassic intracontinental deformation in SW Gondwana. In: M. J. De Wit \& I. D. Ransomc (eds.) Inversion tectonics of the Cape Fold Belt, Karoo and Cretaceous basins of Southern África. Balkema, p. 23-26.

Cole, D.1.1992. Evolution and development of the Karoo Basin. In: M-. J. De Wit \& I. D. Ransomc (eds.) Inversion tectonics ofthe Cape Fold Belt, Karoo and Cretaceous basins of Southern Africa. Balkema, p. 87-100

Cordani, U.G.; Neves, B.B.B.; Fuck, R.A.; Porto, R.; Thomaz Filho, A.; Cunha, F.M.B. 1984 Estudo preliminar de integração do Pré-Cambriano com os eventos tectônicos das bacias sedimentares brasileiras. Rio de Janeiro: PETROBRÁS, Série Ciência-Técnica-Petróleo n. $15,70 \mathrm{p}$.

Coutinho, J.M.V.; Hachiro, J.; Coimbra, A.M.; Santos, P.R. 1991. Ash-fall derived vitroclastic tuffaceous sediments in the Permian of the Paraná Basin and their provenancc. In: Gondwana Seven, São Paulo, 1988. Proceedings..., São Paulo: Universidade de São Paulo, p. 147-160.

Cowie, J.W. \& Bassett, M.G. 1989. IUGS Global stratigraphic chart. Episodes, 12 (2).

De Wit, M.J.; Jeffery, M.; Bergh, H.; Nicolaysen, L. 1988. Geológical map of sectors of Gondwana, reconstructed to their disposition 150 Ma. Tulsa: American Association of Petroleum Geologists/University of Witwatersrand, escala 1:10 000000.

Díaz-Martínez, E. 1995. Devonico Superior y Carbonífero del Altiplano de Bolivia - estratigrafia, sedimentologia y evolución paleogeográfica. La Paz: Informes de ORSTOM Bolivia, $\mathrm{n}$. $46,164 \mathrm{p}$

Du Toit, A.L. 1927. A geological comparison of South America with South Africa. Washington: The Carnegie Institution, publ. 381, $157 \mathrm{p}$.

Eyles, C.H.; Eyles, N.; França, A.B. 1993. Glaciation and tectonics in an active intracratonic basin: the Late Palaeozoic Itararé Group, Paraná Basin, Brazil. Sedimentology, 40:1-25.

Fernández-Seveso, F.; Perez, M.A.; Brisson, I.E.; Alvarez, L. 1993. Sequence stratigraphy and tectonic analysis of the Paganzo Basin, West Argentina. Comptes Rendas XIIICC-P, 2:223-260

Fernández-Seveso, F. \& Tankard, A.J. 1995. Tectonics and stratigraphy of the Late Paleozoic Paganzo Basin of Western Argentina and its regional implications. In: A. J. Tankard; R. Suárez Soruco; H. J. Welsink (eds.) Petroleum hasins of South America. Tulsa: American Association of Petroleum Geologists Memoir 62, p. 285-301.

França, A.B.; Milani, E.J.; Schneider, R.L.; Lópcz-Paulsen, O.; López-Pugliessi, J.M.; Suárez S., R.; Santa Ana, H.; Wiens, F.; Ferreiro, O.; Rossello, E.A.; Bianucci, H.A.; Flores, R.F.A.; Vistalli, M.C.; Fernández-Seveso, F.; Fuenzalida, R.P.; Mufioz, N. 1995. Phancrozoic correlation in Southern South America. In: A. J. Tankard; R. Suárez Soruco; H. J. Welsink (eds.) Petroleum basins of South America. Tulsa: American Association of Petroleum Geologists Memoir 62, p. 129-161.

França, A.B.; Trigüis, J.A.; Anjos, S.M.C.; Milani, E.J.; Wolff, S. 1994. Projeto Ponta Grossa. Curitiba: PETROBRÁS, 2 v. (relatório interno)

Furque, G. 1965. Geologia de Ia región del Cerro Ia Bolsa (Província de La Rioja). In: Segundas Jornadas Geológicas Argentinas, 1965. Actas... Buenos Aires: AGA, p. 181-215.

Gohrbandt, K.H.A. 1993. Paleozoic paleogeographic and dcpositional devclopments on the central proto-Pacific margin of Gondwana: their importancc to hydrocarbon accumulation. Journal of South American Earth Sciences, 6(4):267-287.

Hallam, A. 1984. Pre-Quaternary sea-level changes. Annual Review ofthe Earth and Planetary Science Letters, 12:205-243.

Iñiguez, A.M.; Valle, A.; Poiré, D.G.; Spaletti, L.A.; Zalba, P.E. 1989. Cuenca precambrica/paleozoica inferior de Tandilia, Província de Buenos Aires. In: G. A Chebli $\&$ L. A. Spalletti (eds.) Cuencas sedimentarias argentinas. Tucuman: Universidad Nacional, Serie Correlacion Geológica, n. 6, p. 245-264.

Johnson, J.G. 1971. Timing and coordination of orogenic, epeirogenic and eustatic events. Geological Society of America Bulletin, 82:3263-3298.

Johnson, M.R. 1991. Sandstone petrography, provenance and plate tectonic sctting in Gondwana context of the southeastern Cape-Karoo Basin. South African Journal of Geology, 94:137-154.

Kay, S.M.; Ramos, V.A.; Mpodozis, C.; Sruoga, P. 1989. Late Paleozoic to Jurassic silicic magmatism at the Gondwanaland margin: analogy to the Middle Proterozoic in North America? Geology, 17(4):324-328.

Keidel, J. 1916. La geologia de Ias sierras de Ia Provincia de Buenos Aires y sus relaciones con Ias montarias de Sud África y los Andes. Buenos Aires: Anales del Ministério de Agricultura de Ia Nación, Sección Geologia, Mineralogia y Mincría, IX, 3:1-78.

Klein, G.D. 1995. Intracratonic basins. In: C. J. Busby \& R. V. Ingersoll (eds.) Tectonics of sedimentary basins. Blackwell Science, p. 459-478.

Kokogian, D.A.; Fernández-Seveso, F.; Mosquera, A. 1993. Las secuencias sedimentarias triasicas. In: V. A. Ramos (ed.) Geologia y recursos naturales de Mendoza. Buenos Aires: Asociación Geológica Argentina/Instituto Argentino del Petróleo y del Gás, p. 65-78.

Leighton, M.W. \& Kolata, D.R. 1990. Selected interior cratonic basins and their placc in the scheme of global tectonics - a synthesis. In: M. W. Leighton; D. R. Kolata; D. F. Oltz; J. J. Eidel (eds.) Interior cratonic basins. Tulsa: American Associalion of Petroleum Geologists Memoir 51, p. 729-797.

López-Gamundí, O.R.; Conaghan, P.J.; Rossello, E.A.; Cobbold, P.R. 1995. The Tunas Formation (Permian) in the Sierras Australcs Foldbelt, east central Argentina -evidence for syntectonic sedimentation in a foreland basin. Journal of South American Earth Sciences, 8(2): 129-142.

López-Gamundí, O.R.; Espejo, I.S.; Conaghan, P.J.; Powell, C.M.A. 1994. Southern South America. In: J. J. Veevers \& C. M. A. Powell (eds.) Permian-Triassic Pangean basins and foldbelts along the Panthalassan margin of Gondwanaland. Boulder: Geological Society of America Memoir 184, p. 281-329.

López-Gamundí, O. \& Rossello, E.A. 1993. Devonian-Carboniferous unconformity in Argentina and its relation to Eo-Hercynian orogeny in southern South America. Geologische Rundschau, 82:136-147.

López-Gamundí, O. \& Rossello, E.A. Common evolutionary patterns along the Samfrau geosynclinc: the Sauce Grande Basin-Ventana foldbelt (Argentina) and Karoo Basin-Cape foldbelt (South África) revisited. Geologische Rundschau (no prelo).

Marques, A.; Zanotto, O.A.; França, A.B.; Astolfi, M.A.M.; Paula, O.B. 1993. Compartimentaçã tectônica da Bacia do Paraná. Curitiba: PETROBRÂS/ NEXPAR, 87 p. (relatório interno).

Melo, J.H.G. 1988. The Malvinokaffric realm in the Devonian of Brazil. In: N. J. Mcmillan; A F. Embry; D. J. Glass (eds.) Devonian of the world. Calgary: Canadian Society of Petroleum Geologists Memoir 14, v. I, p. 669-704.

Milani, E.J. 1992. Intraplate tectonics and the evolution of the Paraná Basin, S Brazil. In: M. J. De Wit \& I. D. Ransome (eds.) Inversion tectonics of the Cape Fold Belt, Karoo and Cretaceous basins of Southern Africa. Balkema, p. 101-108.

Milani, E.J. 1997. Evolução tectono-estratigráfica da Bacia do Paraná e seu relacionamento com

a geodinâmica fanerozóica do Gondwana sul-ocidental. Instituto de Geociências,

Universidade Federal do Rio Grande do Sul, Tese de Doutoramento, $255 \mathrm{p}$.

Milani, E.J.; Assine, M.L.; Soares, P.C.; Daemon, R.F. 1995. A Sequência Ordovício-Siluriana da Bacia do Paraná. Boletim de Geociências da PETROBRAS, 9(2/4):301-320.

Mizusaki, A.M.P. 1989. Análise petrográfica e dotação radiométrica do poço 2-TL-l-MS (testemunhos 39 e 40). Rio de Janeiro: PETROBRÁS/CENPES, 8 p. (relatório interno).

Pezzi, E.E. \& Mozetic, M.E. 1989. Cuencas sedimentarias de Ia región Chacoparanense. In: G.A. Chebli \& L. A. Spalletti (eds.) Cuencas sedimentarias argentinas. Tucuman: Universidad Nacional, Serie Correlacion Geológica, n. 6, p. 65-78

Powell, C.M.A. 1993. Assembly of Gondwanaland -open fórum. In: Gondwana Eight, Proceedings... Balkema, p. 219-237.

Quinlan, G.M. \& Beaumont, C. 1984. Appalachian thrusting, lithospheric flexure, and the Paleozoic stratigraphy of the Eastern interior of North America. Canadian Journal of Earth Sciences, 21:973-996.

Ramos, V.A. 1988. Late Proterozoic - Early Paleozoic of South America - a collisional history. Episodes, 11(3):168-174.

Ramos, V.A. 1990. Field guide to geology ofthe Central Andes ( $\left.31^{\circ}-33^{\circ} \mathrm{SL}\right)$. Buenos Aires: Universidad de Buenos Aires, Central Andes Field Seminar, $68 \mathrm{p}$

Ramos, V.A. 1993. Interpretación tectônica. In: V. A. Ramos (ed.) Geologia y recursos naturales de Mendoza. Buenos Aires: Asociación Geológica Argentina/Instituto Argentino del Petróleo y del Gás, p. 257-268

Ramos, V.A.; Jordan, T.E.; Allmendinger, R.W.; Kay, S.M.; Cortes, J.M.; Palma, M.A. 1984 Chilenia: un terreno aloctono cn Ia evolución paleozóica de los Andes centrales. In: Congreso Geológico Argentino, 9. Buenos Aires, Actas... Buenos Aires, Asociación Geológica Argentina, v. 2:84-106.

Ramos, V.A.; Jordan, T.E.; Allmendinger, R.W.; Mpodozis, C.; Kay, J.M.; Cortes, J.M.; Palma, M. 1986. Paleozoic terranes of the central Argentine-Chilean Andes. Tectonics, 5(6):855-880.

Ramos, V.A. \& Vujovoch, G. I. 1993. Alternativas de Ia evolución del borde occidental de America del Sur durante el Proterozóico. Revista Brasileira de Geociências, 23(3): $194-200$

Ramos, V.A.; Vujovich, G.L; Dallmeyer, R.D. 1996. Los klippes y ventanas tectónicas de Ia estructura prcándica de Ia Sierra de Pie de Paio (San Juan): edad y implicaciones tectónicas. In: Congreso Geológico Argentino y Congreso de Exploración de Hidrocarburos, 13/3, 1996. Actas... Buenos Aires: Asociación Geológica Argentina y Instituto Argentino del Petróleo y del Gás, v. 5, 377-392.

Sempere, T. 1995. Phanerozoic evolution of Bolívia and adjacent regions. In: A. J. Tankard; R. Suárez Soruco; H. J. Welsink (eds.) Petroleum basins of South America. Tulsa: American Association of Petroleum Geologists Memoir 62, p. 207-230.

Sloss, L.L. 1963. Sequences in the cratonic interior of North America. Geological Society of America Bulletin, 74:93-114

Sloss, L.L. 1972. Synchrony of Phanerozoic sedimentary-tectonic events of the North American craton and the Russian platform. In: International Geological Congress, 24. Proceeedings... Montreal: International Union of Geological Sciences, p. 24-32.

Soares, P.C. 1991. Tectônica sinsedimentar cíclica na Bacia do Paraná - controles. Departamento de Geologia, Universidade Federal do Paraná, Monografia para concurso de Professor Titular, $131 \mathrm{p}$.

Soares, P.C.; Landim, P.M.B.; Fulfaro, V.J. 1978. Tectonic cycles and sedimentary sequences in the Brazilian intracratonic basins. Geological Society of America Bulletin, 89:181-191.

Steckler, M. \& Watts, A.B. 1978. Subsidence of the Atlantic-type continental margin off New York. Earth and Planetary Science Letters, 41:1-13.

Suess, E. 1906. The face of the Earth. Clarendon Press, $759 \mathrm{p}$.

Urien, C.M.; Zambrano, J.J.; Yrigoyen, M.R. 1995. Petroleum basins of South America - an ovcrvicw. In: A. J. Tankard; R. Suárez Soruco; H. J. Welsink (eds.) Petroleum basins of South America. Tulsa: American Association of Petroleum Geologists Memoir 62, p. 63-78.

Vail, P.R.; Mitchum, R.M.; Thompson, S. 1977. Scismic straligraphy and global changes of sca level, part 3: rclativc changes of sea level from coastal onlap. In: C. E. Payton (cd.) Seismic stratigraphy - applications to hydrocarbon exploration. Tulsa: American Association of Petroleum Geologists Memoir 26, p. 63-81.

Veevers, J.J.; Cole, D.I.; Cowan, E.J. 1994. Southern África: Karoo Basin and Cape Fold Belt In: J. J. Veevers \& C. M. A. Powell (eds.) Permian-Triassic Pangean basins and foldbelts along the Panthalassan margin of Gondwanaland. Boulder: Geological Society of America Memoir 184, p. 223-280.

Visser, J.N.J. 1990. The age of the glacigene deposits in Southern África. South African Journal of Geology, 93:366-375.

Williams, K.E. 1995. Tectonic subsidence analysis and Paleozoic paleogeography of Gondwana In: A. J. Tankard; R. Suárez Soruco; H. J. Welsink (eds.) Petroleum basins of South America. Tulsa: American Association of Petroleum Geologists Memoir 62, p. 79-100.

Zalán, P.V.; Wolff, S.; Astolfi, M.A.M.; Vieira, I.S.; Conceição, J.C.J.; Appi, V.T.; Neto, E.V.S.; Cerqucira, J.R.; Marques, A. 1990. The Paraná Basin, Brazil. In: M. W. Leighton; D. R. Kolata; D. F. Oltz; J. J. Eidel (eds.) Interior cratonic hasins. Tulsa: American Association of Petroleum Geologists Memoir 51,p. 681-708. 